\title{
Lower Salaries and No Options? On the Optimal Structure of Executive Pay ${ }^{1}$
}

\author{
Ingolf Dittmann ${ }^{2} \quad$ Ernst Maug ${ }^{3}$ \\ First Draft: November 15, 2003 \\ This Version, October 20, 2005 \\ Forthcoming in the Journal of Finance
}

\begin{abstract}
${ }^{1}$ We are grateful to Axel Adam-Müller, Nemmara Chidambaran, Wayne Guay, Michel Habib, Dirk Jenter, Christian Laux, Kai Li, Bob Miller, Kristian Rydqvist, Stefan Winter, David Yermack and seminar participants at the Accounting Research Workshop (Bern), the Haifa-Humboldt Workshop (Haifa), the Ottobeuren meetings, Erasmus University Rotterdam, Hong Kong University of Science and Technology, London School of Economics, McIntire School of Business (University of Virginia), Université Paris Dauphine, University of Frankfurt/M., University of Konstanz, University of Mannheim, and University of Zurich for clarifying discussions and suggestions on an earlier draft of this paper. In addition, the paper greatly benefitted from the comments of an anonymous referee. We also thank Oliver Spalt for excellent research assistance. We gratefully acknowledge financial support from the Rudolf von Bennigsen-Foerder Foundation and from the Deutsche Forschungsgemeinschaft through the SFB 649 "Economic Risk."

${ }^{2}$ Erasmus University Rotterdam, P.O. Box 1738, 3000 DR Rotterdam, The Netherlands. Email: dittmann@few.eur.nl. Tel: +31 104081283.

${ }^{3}$ University of Mannheim, Chair for Corporate Finance, 68131 Mannheim, Germany. Email: maug@bwl.uni-mannheim.de.
\end{abstract}




\title{
Lower Salaries and No Options? On the Optimal Structure of Executive Pay
}

\begin{abstract}
We estimate a standard principal agent model with constant relative risk aversion and lognormal stock prices for a sample of 598 US CEOs. The model is widely used in the compensation literature, but it predicts that almost all of the CEOs in our sample should hold no stock options. Instead, CEOs should have lower base salaries and receive additional shares in their companies. For a typical value of relative risk aversion, almost half of the CEOs in our sample would be required to purchase additional stock in their companies from their private savings. The model predicts contracts that would reduce average compensation costs by $20 \%$ while providing the same incentives and the same utility to CEOs. We investigate a number of extensions and modifications of the standard model, but find none of them to be satisfactory. We conclude that the standard principal agent model typically used in the literature cannot rationalize observed contracts. One reason may be that executive pay contracts are suboptimal.
\end{abstract}

JEL Classification: G30, M52

Keywords: Executive Compensation, Stock Options 
"We don’t give options because it would be a lottery ticket." (Warren Buffet)

"There will be no new stock option grants from Microsoft. Instead, we will award actual stock to our employees." (Steve Ballmer, Microsoft)

\section{Introduction}

This paper analyzes the optimal structure of CEO pay, or, more specifically, the optimal balance between stock, options and base salary in executive compensation contracts. We develop a new methodology to estimate and test efficient contracting models and apply it to a model of efficient contracting that is widely used in the literature on executive compensation. This model assumes constant relative risk aversion and lognormally distributed stock prices. On this basis we determine optimal contracts for a sample of CEOs and conclude that the model cannot generate observed contracts. In particular, it rarely predicts options. We explore a number of alternative modeling approaches but find none of them to be convincing. We conclude that we need a different contracting model to understand salient features of executive compensation contracts. Our results would also be consistent with the view that observed compensation practice suffers from significant defects and therefore cannot be explained by an efficient contracting model.

The literature on the structure of executive compensation contracts has developed two complementary perspectives on executive stock options. ${ }^{1}$ One perspective highlights the fact that stock options are "expensive" because they are risky (e. g. Oyer and Schaefer, 2005). For typical parameter values, an option that is worth $\$ 100$ to diversified investors may be worth only $\$ 20-\$ 40$ to an undiversified, risk-averse CEO. This perspective emphasizes the participation constraint of the CEO, but it neglects incentives. From another perspective, stock options are "cheap" because they provide more incentives for the same dollar outlay than an equivalent investment in stock, so companies save on compensation costs for providing incentives (e. g. Hall and Murphy, 2000). This perspective focuses only on the incentive compatibility constraint. We bring these two perspectives together in the context of a complete contracting model and argue that their relative importance depends on whether the model also features downward constraints on fixed salaries.

To illustrate this point, consider a simple numerical example. Suppose a company can provide

\footnotetext{
${ }^{1}$ Despite the long list of references at the end of this paper, we make no attempt here to survey the large literature on executive stock options, let alone the still larger literature on executive compensation. Excellent surveys on various aspects of the subject include Abowd and Kaplan (1999), Murphy (1999), Prendergast (1999), Core, Guay, and Larcker (2002), and Hall and Murphy (2003).
} 
the same incentives (and therefore induce the same action by the CEO) with either one share with a market value of $\$ 100$ and a subjective value (certainty equivalent) of $\$ 40$, or with options with a market value of $\$ 95$ and a subjective value of $\$ 25$.

\section{Stock Options}

\begin{tabular}{|c|c|c|c|}
\hline & Market Value & $\$ 100$ & $\$ 95$ \\
\hline- & Subjective Value & $\$ 40$ & $\$ 25$ \\
\hline & Risk Premium & $\$ 60$ & $\$ 70$ \\
\hline
\end{tabular}

If base salaries are rigid, then only market values are relevant and options are always a cheaper way to provide the same incentives. In this example, the company saves $\$ 5(=\$ 100-\$ 95)$ by using options. If the CEO's base salary is variable however, then stock dominates options. In this case, the company incurs additional compensation costs of $\$ 70$ if incentives are provided through options (award options worth $\$ 95$, reduce base salary by $\$ 25$ ). The same incentives cost the company only $\$ 60$ if incentives are provided with stock. We argue that the situation described in this numerical example is the empirically relevant one.

We therefore calibrate a principal agent model of efficient contracting that has become standard in the literature on executive compensation contracts, especially in quantitative analyses of the design features of these contracts. The model combines preferences with constant relative risk aversion (CRRA) and lognormally distributed prices. Applications of this model to executive compensation date back at least to Lambert, Larcker, and Verrecchia (1991). ${ }^{2}$ Other models, like those using preferences with constant absolute risk aversion or normally distributed prices, are seldom used, and mostly to generate qualitative results and closed form solutions, rarely to estimate, calibrate, or simulate models or to obtain quantifiable results. ${ }^{3}$ Hence, we feel entitled to argue that our modeling approach implements a variant of the "conventional" model.

\footnotetext{
${ }^{2}$ CRRA preferences and lognormal prices have been used by Lambert, Larcker, and Verrecchia (1991), Hall and Murphy (2000), (2002), Himmelberg and Hubbard (2000), Hall and Knox (2004), Jenter (2002) and Oyer and Schaefer (2003). Closely related are models that combine CRRA-preferences with geometric binomial trees or geometric Brownian motion models of stock price development that generate identical or similar distributions of stock prices. Binomial models were used by Huddart (1994) and Carpenter (1998), Brownian motion models by Tian (2001), Johnson and Tian (2000a), (2000b), and Ingersoll (2002).

${ }^{3}$ Feltham and $\mathrm{Wu}$ (2001) and Baker and Hall (2004) use CARA-normal models. Nohel and Todd (2005) use CRRA-preferences with a uniform distribution, Henderson (2002) uses CARA-preferences with geometric Brownian motions, and Carpenter (2000) uses hyperbolic absolute risk aversion (HARA). Hemmer, Kim, and Verrecchia (2000) use HARA-utility and a Gamma-distribution in an analytic model. Haubrich and Popova (1998) is one of the few studies that use CARA-preferences in a calibration exercise. They also use a discrete state space model. Lambert and Larcker (2004) use CRRA-preferences with a truncated normal distribution of stock prices.
} 
We develop a new methodology to applying and testing this model: We first reformulate the model so that it can be calibrated to an individual CEO with publicly available data. We then estimate the relevant model parameters for a sample of 598 CEOs. In particular, we aggregate option holdings into a representative option and estimate wealth from previous years' income of the CEO. For risk aversion we use a grid of values that cover the range which other researchers have suggested as plausible. Then we numerically determine the optimal contract for each level of risk aversion and each CEO in our dataset. Finally, we compare the optimal contracts implied by the model with the actual contracts we observe and evaluate whether they are statistically and economically different.

Our main result is that the model cannot account for a prominent feature of $96 \%$ of the CEOs in our sample: we almost never obtain stock options as part of an optimal contract. While the CEOs in our sample hold on average options on $1.3 \%$ of their companies, the model cannot account for more than $0.1 \%$ even for very low levels of risk aversion and predicts that most CEOs should not have any stock options at all. An immediate implication is that CEOs should also receive lower base salaries and more restricted stock. Indeed, for a typical level of risk aversion, $47 \%$ of the CEOs in our sample should receive no base salary at all and use some of their private savings to purchase additional stock in their companies. The efficiency gains implied by the model are economically significant. We find that contracts that provide the same level of expected utility and the same incentives to the CEO would be cheaper by $20 \%$ or $\$ 12.3$ million on average.

We investigate some generalizations of this set-up and allow for more general contracts. Firstly, we drop the constraint that option holdings must be non-negative. It turns out that this constraint is binding in almost all cases and optimal unconstrained contracts have much higher stock holdings (more than twice the observed level) as well as negative option holdings such that pay for performance sensitivities for higher stock prices are generally positive but small. In order to benchmark our results we also calibrate the general nonlinear contract that is theoretically optimal. This shows that the conventional (CRRA-lognormal) model implies concave contracts that emphasize 'sticks' over 'carrots': the penalties for stock price decreases are large, whereas the additional pay for stock price increases is small. By comparison, observed contracts emphasize 'carrots' and feature large gains for stock price increases but protect the CEO against large losses. In principle, the general nonlinear contract could be implemented by firing the CEO for significant underperformance, but observed contributions of CEO-turnover to pay for performance-sensitivity are much smaller than 
implied by the contracts found by the conventional model. ${ }^{4}$

A number of papers argue that options are awarded to provide risk-taking incentives, so that the CEO is willing to adopt projects that increase value and risk. ${ }^{5}$ We therefore analyze whether the optimal contracts implied by our model change the CEO's risk tolerance relative to observed contracts. We find that the optimal contract with non-negative option holdings only slightly reduces risk taking incentives. This effect appears too weak to explain the option holdings in observed contracts.

We recompute all our results for a model that incorporates personal and corporate taxes. We document the tax advantage of options, but this aspect does not change our main results. We also check for possibly incorrect measurements of wealth and contract convexity, as well as for alternative distributional assumptions. We find that our analysis is robust to errors in these three dimensions. Similarly, we argue that hedging by the CEO through trading in the stock market is unlikely to change our results. We conclude that the standard version and several variants of the principal agent model cannot accommodate stock options, so that this model is also ill-suited to analyze design features of stock option contracts. ${ }^{6,7}$

We can reconcile the model with observed contracts by assuming that base salaries cannot be adjusted downward, just as suggested by the example above. The reason is that a decrease in options is always associated with a decrease in base salary and an increase in stock holdings. We find only limited support for the implications of this assumption and regard this way to fix the model as implausible. Taking an altogether different perspective, our results could be cited as supporting evidence for the view that CEO compensation does not conform to the efficient contracting paradigm, and that stock options are a vehicle for rent extraction. ${ }^{8}$ We discuss this view in the concluding section.

\footnotetext{
${ }^{4}$ The literature on CEO turnover goes back at least to Coughlan and Schmidt (1985). See also Kaplan (1994). Brickley (2003) summarizes the subsequent discussion by arguing that the economic significance of CEO turnover is small.

${ }^{5}$ This argument goes back to Smith and Stulz (1985). We discuss the literature on this topic in greater detail below.

${ }^{6}$ Several design features have been analyzed in the literature. Hemmer, Matsunaga, and Shevlin (1998) and Huddart, Jagannathan, and Saly (1999) discussion reloading. Meulbroek (2001) models indexing of strike prices, and Hall and Murphy (2000) analyze optimal strike prices. The valuation model of Sircar and Xiong (2003) allows for resetting as well as reloading.

${ }^{7}$ Core, Guay, and Larcker (2002) also recognize this limitation of existing research in their survey. Oyer and Schaefer (2005) reject explanations for stock options based on incentives for non-executive employees. Core, Guay, and Verrecchia (2003) provide more evidence against the standard principal agent model based on the analysis of non-price performance measures.

${ }^{8}$ Bebchuk and Fried (2004) regard the observed structure of executive compensation as evidence for rent extraction. Bertrand and Mullainathan (2000) adopt this view only for companies that have weak governance systems.
} 
Our empirical approach is new and compares with two other methodologies that are widely applied in the literature. ${ }^{9}$ Several authors have calibrated a model like ours in order to analyze various aspects of executive compensation contracts by making parametric assumptions about a "typical" CEO. ${ }^{10}$ However, then conclusions are sensitive to parametric assumptions that differ across CEOs, so calibrating the model to observed parameter values of individual CEOs puts our conclusions on a firmer empirical foundation. An alternative approach is to explore the implications of efficient contracting models using regression analysis. ${ }^{11}$ Cross-sectional regressions test the qualitative, directional implications of theoretical models, whereas our approach also tests the quantitative implications, which is a more stringent test. However, we have to make additional assumptions about functional forms that are absent from reduced-form regressions. To the best of our knowledge, the only structural test of a principal agent model of compensation is Margiotta and Miller (2000), who do not look at options and cannot reject the implications of their model.

The following Section 2 develops the theoretical model in detail. Section 3 explains our empirical methodology and how to implement the model. Section 4 presents and discusses our empirical results for alternative contracting environments. Section 5 evaluates the implications of these contracts for investment incentives. Section 6 performs a number of robustness checks on our analysis. In Section 7 we investigate modifications of the base model that may help to reconcile it with the empirical evidence. In Section 8 we summarize or findings and present some further thoughts about the limitations of our approach and directions for future research. The more technical aspects of our analysis can be found in the appendix.

\footnotetext{
${ }^{9}$ See also Garen (1994), Haubrich (1994), Haubrich and Popova (1998), and Margiotta and Miller (2000) for different econometric approaches. None of these studies allows for stock options. Hall and Murphy (2002) conclude that stock options "are a particularly expensive way to convey compensation," but they do not investigate the relative costs of providing incentives.

${ }^{10}$ The closest paper to ours based on this paradigm is Lambert and Larcker (2004), who solve a complete principal agent model and seem to come to different conclusions from ours. We discuss their work below. An incomplete list of calibration exercises includes Lambert, Larcker, and Verrechia (1991), Hall and Murphy (2000), (2002), Hall and Knox (2004), and Jenter (2002).

${ }^{11}$ See the literature cited in footnote 39 below and the discussion in the survey of Core, Guay, and Larcker (2002), section 3.2. Some papers find results that support the principal agent model, e. g. Aggarwal and Samwick (1999), and Kedia and Mozumdar (2002). Others come to different conclusions, e. g. Core and Guay (2002b) who contradict Aggarwal and Samwick's findings on methodological grounds, and Yermack (1995), who reports that variables associated with agency models explain almost none of the cross-sectional variation in the use of options.
} 


\section{Theoretical Model}

We develop a single-period principal agent framework, following Holmström (1979). The riskneutral principal (shareholders) offers a contract to the risk-averse and effort-averse agent (CEO). The CEO consumes only at date $T$, which marks the end of the period. At this point in time the market value of the firm equals $P_{T}$. We ignore leverage and do not distinguish between the market value of equity and the market value of the firm. The principal cannot observe the agent's effort directly. As a consequence, the contract cannot be a function of effort, but it can be a function of $P_{T}$.

Technology and Uncertainty. The end of period value of the firm $P_{T}$ depends on the effort $e$ of the CEO, $e \in[0 ; \infty)$, and a standard normal random variable $u$. We use risk-neutral pricing throughout and denote the risk-free rate of interest by $r_{f}$. We will discuss our valuation approach in greater detail below (see p. 7 ). We specify: ${ }^{12}$

$$
P_{T}(u, e)=P_{0}(e) \exp \left\{\left(r_{f}-\frac{\sigma^{2}}{2}\right) T+u \sqrt{T} \sigma\right\}, u \sim N(0,1)
$$

Hence, the distribution of $P_{T}(u, e)$ is log-normal with expected present value under the risk-neutral density equal to $P_{0}=E\left[P_{T} \exp \left\{-r_{f} T\right\}\right] .{ }^{13} P_{0}(e)$ satisfies standard monotonicity and concavity assumptions typically made for production functions, so $\frac{\partial P_{0}}{\partial e}>0$ and $\frac{\partial^{2} P_{0}}{\partial e^{2}}<0$. In any rational expectations equilibrium, $P_{0}$ is equal to the market value of equity at the effort level $e^{*}$ chosen by the manager under the given contract, so $P_{0}\left(e^{*}\right)$ is equal to the observed market capitalization.

Permissible Contracts. We initially assume that the contract can be described by three parameters: a base salary $\phi$, the number of shares in the company $n_{S}$ (expressed as a fraction of all shares outstanding), and the number of options on the company's stock $n_{O}$ (also expressed in terms of the number of shares outstanding). We further assume that all options granted to the CEO have identical maturity $T$ and strike price $K$. We will later discuss extensions of our base model to allow for multiple strike prices. The strike price $K$ is expressed as the strike price for $n_{O}=1$, i.e., for

\footnotetext{
${ }^{12}$ This expression assumes a company that does not pay dividends. For a company that pays dividends, $P_{0}(e)$ needs to be replaced with $P_{0}(e) \exp \{-d T\}$ for the purpose of valuing options, where $d$ is the dividend yield. We adjust for dividends in our empirical work but abstract from them here (see also the discussion below Table 1 on p. 14). The density of the lognormal distribution is given in equation (21) in the appendix.

${ }^{13}$ Here and in the following all expectations are taken with respect to the probability distribution of $u \sim N(0,1)$. We should really write $P_{0}=E\left[P_{T}(u, e) e^{-r_{f} T}\right]$ and also write $W_{T}, \pi_{T}$, etc. below as functions of $u$. However, we submerge reference to $u$ for ease of exposition.
} 
the whole company. We denote by $W_{0}$ the wealth of the CEO that is not invested in the firm's securities as of time $t=0$ and refer to it as "non-firm wealth." We assume that she invests all her non-firm wealth at the risk-free rate $r_{f}$, so her end of period wealth (at date $T$ ) is:

$$
W_{T}=\left(\phi+W_{0}\right) \exp \left\{r_{f} T\right\}+n_{S} P_{T}(u, e)+n_{O} \max \left\{P_{T}(u, e)-K, 0\right\} .
$$

Note that this specification implicitly assumes that base pay (including bonus payments) is paid out today and invested, while all other components of pay lead to cash flows to the CEO at date $T$.

Preferences. The CEO's utility is separable in wealth and effort and has constant relative risk aversion with risk-aversion parameter $\gamma:{ }^{14}$

$$
U\left(W_{T}, e\right)=V\left(W_{T}\right)-C(e)=\frac{W_{T}^{1-\gamma}}{1-\gamma}-C(e)
$$

The costs of effort are assumed to be given by some convex cost function $C(e)$ with $\frac{\partial C}{\partial e}>0$ and $\frac{\partial^{2} C}{\partial e^{2}}>0$. We assume that the CEO has outside employment opportunities that give her expected utility $\bar{U}$. Expected utility is $E\left[U\left(W_{T}, e\right)\right]$, where expectations are taken with respect to the distribution of $W_{T}$ from (2).

Risk-Neutral Pricing. We assume risk-neutral pricing in order to ensure consistency of our approach. This is necessary as we do not distinguish between firm-specific risk and market risk. We require that a risk-neutral CEO should value options in the same way as a diversified market, which implies that the certainty equivalent value of one option converges to its Black-Scholesvalue as risk aversion $(\gamma)$ converges to zero in the context of our model. Suppose by contrast we would introduce a risk-premium $\mu>r_{f}$ on the company's stock in the present model, without also allowing the CEO to trade in the stock market to obtain the market risk premium. Then any CEO with sufficiently low risk aversion (low $\gamma$ ) would value the company's stock and stock options higher than the market and the certainty equivalent would exceed the Black Scholes value. The reason is that investing in her own company's securities would be the only way the CEO could then obtain an expected return above the risk-free rate. In order to avoid the paradoxical outcome

\footnotetext{
${ }^{14}$ If $\gamma=1$, we define $V\left(W_{T}\right)=\ln \left(W_{T}\right)$. We do not use $\frac{W_{T}^{1-\gamma}-1}{1-\gamma}$ (which would make $U\left(W_{T}, e\right)$ continuous in $\gamma$ at $\gamma=1$ ) for numerical reasons.
} 
that the CEO is willing to pay a premium above the market price on her company's securities, we work with risk-neutral pricing in (1). Effectively, this amounts to the assumption that all risk in the model is firm-specific. We discuss this further in Section 6 below and argue that the implied approximation error is small. By contrast, the opposite assumption - treating all risk as systematic - would seriously bias our results. ${ }^{15}$

Theoretical Solution. We apply the two-stage approach of Grossman and Hart (1983) and ask which contract is optimal for implementing a given level of effort. Denote the pay of the manager in currency units of time $T$ by

$$
\pi_{T}=\phi \exp \left(r_{f} T\right)+n_{S} P_{T}+n_{O} \max \left\{P_{T}-K, 0\right\}
$$

Note that $W_{T}=W_{0} \exp \left\{r_{f} T\right\}+\pi_{T}$. We denote the present value of expected pay by $\pi_{0}=$ $E\left[\exp \left\{-r_{f} T\right\} \pi_{T}\right]$. Then:

$$
\pi_{0}=\phi+n_{S} P_{0}+n_{O} B S
$$

where $B S$ is the Black-Scholes value of the option. The principal's problem then is to find the contract that implements the chosen effort level $\bar{e}$ with the lowest costs:

$$
\begin{gathered}
\min _{\left(\phi, n_{S}, n_{O}\right)} \pi_{0}=\phi+n_{S} P_{0}+n_{O} B S \\
\text { s.t. } E\left[U\left(W_{T}, \bar{e}\right)\right] \geq \bar{U}, \\
\bar{e}=\arg \max _{e \in[0, \infty)} E\left[U\left(W_{T}, e\right)\right], \\
0 \leq n_{S} \leq 1, \quad n_{O} \geq 0 \\
\phi+W_{0} \geq 0 .
\end{gathered}
$$

Here (7) represents the participation constraint, (8) represents the incentive compatibility constraint, and (9) defines admissible contracts. Condition (10) explicitly allows for negative base salaries where the CEO invests some of her initial wealth into her company's securities. However,

\footnotetext{
${ }^{15}$ See Hall and Murphy (2000) and Tian (2001) for other approaches. The latter also concludes that CEOs sometimes value options higher than the market. Cai and Vijh (2005) argue along the same lines as we do and show that introducing the market index reduces the value of options to the CEO.
} 
the CEO cannot pay more than her total initial non-firm wealth. ${ }^{16}$

In a second step, the principal will search over all pairs of effort $\bar{e}$ and minimized $\operatorname{costs} \pi_{0}^{*}(\bar{e})$ in order to find the optimal effort level $e^{*}$. We do not consider this second step in this paper. No matter what the optimal effort level $e^{*}$ is, it must solve the first step of the optimization problem (6) - (10): a given contract is not optimal if the same effort level can be implemented with a less costly contract. It is this implication that we are going to check for observed CEO contracts in the empirical part of this paper.

\section{Empirical Methodology and Data}

\subsection{Empirical Implementation}

Our first step towards developing an implementable version of the model is to apply the first-order approach and to replace (8) with the respective first order condition for utility maximization by the CEO. We then discuss how we validate the applicability of the first-order approach. Hence, we replace the incentive compatibility constraint (8) with the first order condition for (8):

$$
\frac{d}{d e} E\left[U\left(W_{T}, e\right)\right]=E\left[\frac{d V\left(P_{0}\right)}{d P_{0}}\right] \frac{d P_{0}(e)}{d e}-\frac{d C(e)}{d e}=0
$$

Here we have made use of the fact that $P_{0}(e), C(e)$ and their derivatives are not stochastic and can therefore be taken outside of the expectations operator. In order to rewrite (11), we define the utility-adjusted pay for performance-sensitivity, UPPS, as follows:

$$
U P P S=\frac{d}{d P_{0}} \exp \left(-r_{f} T\right) E\left[U\left(W_{T}, e\right)\right]=\exp \left(-r_{f} T\right) E\left[\frac{d V\left(W_{T}\right)}{d W_{T}} \frac{d W_{T}}{d P_{0}}\right]
$$

We can change the order of integration and differentiation in (11) and (12) because the integration limits do not depend on the variables with respect to which we differentiate. We observe that in the case of risk-neutrality $(\gamma=0)$, we have $\frac{d V\left(W_{T}\right)}{d W_{T}}=1$ for all $W_{T}$. Then it is easy to show that UPPS equals $n_{S}+n_{O} N\left(d_{1}\right)$, where $N\left(d_{1}\right)$ is the option delta from the Black-Scholes formula. This is just the standard definition of pay for performance-sensitivity under risk-neutrality that has been widely used in the analysis of executive stock options. This justifies the definition of (12)

\footnotetext{
${ }^{16}$ Our qualitative results do not change if condition (10) is replaced by $\phi \geq 0$. Then $\phi^{*}=0$ whenever program (6) - (10) finds $\phi^{*}<0$.
} 
as a utility-adjusted pay for performance-sensitivity. We can rewrite (11) using (12) as:

$$
\frac{d}{d e} E\left[U\left(W_{T}, e\right)\right]=U P P S \times \frac{d P_{0}(e)}{d e} \exp \left(r_{f} T\right)-\frac{d C(e)}{d e}=0 .
$$

Finally, we rearrange (13) and obtain:

$$
\begin{aligned}
& U P P S=k(e) \\
& \text { where: } k(e) \equiv \frac{\exp \left\{-r_{f} T\right\} d C / d e}{d P_{0} / d e},
\end{aligned}
$$

The function $k(e)$ is well-defined as $d P_{0} / d e>0$ for all effort levels. $k(e)$ depends only on the parameters of the manager's cost function and the technology of the company, but is independent of the parameters of the contract and risk aversion. Equation (15) is a more useful version of the first order condition (11) for our numerical work because UPPS depends only on the observable contract parameters, the CEO's wealth, and her risk-aversion $\gamma$, but not on the unknown functions $P_{0}(e)$ and $C(e)$. The unknown value $k(e)$ can be inferred from the data, because under the null hypothesis that observed contracts are optimal, observed contracts must satisfy $(15): k(e)=$ UPPS $\left(\phi^{d}, n_{S}^{d}, n_{O}^{d} ; \gamma, P_{0}(e)\right)$, where superscripts ' $d$ ' denote the contract parameters of the observed contract ('data'). Similarly, we can calculate the unknown quantities in the participation constraint: $E\left[V\left(W_{T}\left(\phi^{d}, n_{S}^{d}, n_{O}^{d}\right) ; \gamma\right)\right]=\bar{U}+C(e)$. We obtain our final program:

$$
\begin{aligned}
& \min _{\left(\phi, n_{S}, n_{O}\right)} \pi_{0}=\phi+n_{S} P_{0}+n_{O} B S \\
& \text { s.t. } \quad E\left[V\left(W_{T}\left(\phi, n_{S}, n_{O}\right) ; \gamma\right)\right]=E\left[V\left(W_{T}\left(\phi^{d}, n_{S}^{d}, n_{O}^{d}\right) ; \gamma\right)\right], \\
& \quad U P P S\left(\phi, n_{S}, n_{O} ; \gamma, P_{0}\right)=U P P S\left(\phi^{d}, n_{S}^{d}, n_{O}^{d} ; \gamma, P_{0}\right), \\
& \quad 0 \leq n_{S} \leq 1, \quad n_{O} \geq 0, \quad \phi \geq-W_{0} .
\end{aligned}
$$

The only unknown variable that remains in program (16) is $\gamma$, so we use a grid for various values of $\gamma$ between 0.5 and 10. This interval encompasses the range of values for risk aversion that researchers in the field of executive compensation regard as reasonable. ${ }^{17}$ We also calibrated a

\footnotetext{
${ }^{17}$ There is no consensus on the correct value for the Arrow-Pratt measure of relative risk aversion. Campbell, Lo, and McKinlay (1997), ch. 8, discuss the extensive literature in macroeconomics that has suggested values for $\gamma$ up to 10 or 20 in order to reconcile asset pricing models with the equity premium puzzle. Chetty (2003) uses a model of labor supply and finds estimates around 1. Extracting estimates of risk aversion from asset prices has also not converged to a consensus. Ait-Sahalia and Lo (2000) summarize research on the subject (see their Table 7) and report values between 0 and 55. The compensation literature typically uses lower values (e. g. Murphy, 1999, uses 1, 2, and
} 
simple model where the CEO can invest in a diversified portfolio and the risk-free asset and found that values of $\gamma$ much below 2 lead to unrealistic predictions about the CEO's investment policies. ${ }^{18}$ Conditional on using the right value of $\gamma$ and assuming that the optimal contract indeed solves (16), the optimal contract must be equal to the observed contract, i.e. $\left(\phi^{*}, n_{S}^{*}, n_{O}^{*}\right)=\left(\phi^{d}, n_{S}^{d}, n_{O}^{d}\right)$. If the optimal contract differs significantly from the observed contract then either the assumed level of risk aversion $\gamma$ is wrong or the observed contract is not optimal. Program (16) has a very intuitive interpretation: We want to find a contract that provides the CEO with the same utility and the same incentives as the observed contract, but that is less costly to shareholders compared to the observed contract.

The first-order approach allows us to solve program (6) - (10) without making any further assumptions on the cost function $C(e)$ except convexity and further assumptions on the production function $P_{0}(e)$ except concavity. However, the agent's objective $E\left[U\left(W_{T}, e\right)\right]$ may still not be concave in effort and have multiple local optima, as $W_{T}$ is a convex function of $P_{T}$. Then the first-order condition is satisfied at each of these local optima. The modified program (16) suggests an optimal contract $\left(\phi^{*}, n_{S}^{*}, n_{O}^{*}\right)$, that satisfies the first-order condition at the same effort level $\bar{e}$ as the observed contract $\left(\phi^{d}, n_{S}^{d}, n_{O}^{d}\right)$. This shows only that the global optimum under the existing contract remains a local optimum under the contract that solves (16). This does not rule out the possibility that the global optimum for the agent under the new contract implies an entirely different effort level $e \neq \bar{e}$. If the effort level chosen by the agent under the new contract is higher $(e>\bar{e})$, then no problem arises for our approach as this would also imply a higher value for the firm $P>P_{0}$. However, we need to verify that the agent does not choose a lower level of effort under the contract that solves program (16).

In our case, we cannot establish the validity of the first-order approach analytically because we restrict the shape of the optimal contract. Instead, we formulate a sufficient condition for the applicability of the first-order approach and validate it empirically. We prove the following result in Appendix A.

Proposition 1 (First-order approach): Let $\left(\phi^{*}, n_{S}^{*}, n_{O}^{*}\right)$ be the optimal contract that solves $3)$.

${ }^{18}$ Consider a CEO with CRRA-utility who can invest in a market portfolio with $\sigma=0.17$ and a risk premium over the risk-free rate of $4 \%$. Then a CEO with $\gamma=0.5$ would leverage her portfolio and invest $277 \%$ of her wealth in the market portfolio. With $\gamma=1$ she would still invest $138 \%$, with $\gamma=2$ the portfolio would be $69 \%$ in the market and $31 \%$ in the risk-free asset. 
(16). Also, let $\bar{e}$ be the effort level chosen under the existing contract. If

$$
U P P S\left(\phi^{*}, n_{S}^{*}, n_{O}^{*} ; \gamma, P\right) \geq U P P S\left(\phi^{d}, n_{S}^{d}, n_{O}^{d} ; \gamma, P_{0}\right)
$$

for all $P \leq P_{0}$, then the agent will never choose an effort level $e<\bar{e}$ under the new contract $\left(\phi^{*}, n_{S}^{*}, n_{O}^{*}\right)$. If the restriction $n_{O} \geq 0$ in program (16) is relaxed, then condition (17) is always satisfied for all contracts where $n_{O}^{*} \leq 0$.

Proposition 1 implies that checking condition (17) is sufficient to ensure that the CEO will not choose a lower effort level under the optimal contract from program (16) than under the existing contract. We are not concerned about higher effort levels as these lead to higher market values of the firm and would therefore reinforce the claim that the existing contract is not optimal. We validate (17) by checking this condition for a grid of 100 equally spaced values of $P$ in the interval $\left(0, P_{0}\right]$ whenever $n_{O}^{*}>0$.

\subsection{Dataset}

For implementing (16), we need data on the contract parameters $\phi^{d}, n_{S}^{d}$, and $n_{O}^{d}$, the CEO's wealth $W_{0}$, the firm value $P_{0}$, the dividend yield $d$, the option maturity $T$, the strike price $K$, the stock volatility $\sigma$, and the risk free rate $r_{f}$. Our data are constructed from the Compustat ExecuComp Database, which contains compensation data on 21,086 executives from 2.448 firms over the period 1992 to 2000. We first identify all executives in the database who were CEO in 2000 and have a continuous history (as CEO or as another executive with data on ExecuComp) of at least five years (1995-1999) in the database. We focus on CEOs in order to prevent correlations due to multiple observations from the same firm.

We match $P_{0}$ to the market capitalization at the 1999 fiscal year end and take the 1999 values of the dividend yield $d$ and the volatility $\sigma$ directly from the database. The fixed salary $\phi^{d}$ is determined as the sum of salary and bonus in 2000 and includes all types of compensation other than stock and options. ${ }^{19}$ Hence we implicitly assume that bonus payments have no relevance for the CEO's incentives. ${ }^{20}$ We use only current-period data to estimate $\phi^{d}$. This ignores the fact that the CEO receives base salary payments every year between now and $T$. Incorporating this feature

\footnotetext{
${ }^{19}$ More precisely, $\phi^{d}$ is the sum of the following four ExecuComp data types: Salary, Bonus, Other Annual, and All Other Total. We do not include LTIP (long term incentive pay), as these are typically not awarded annually.

${ }^{20}$ This seems defensible. Hall and Liebman (1998) argue that the impact of stock options and stock on CEO wealth dwarfs the impact of bonus payments.
} 
would have the same numerical impact as an increase in non-firm wealth $W_{0}$, which we study below. We therefore abstract from this feature.

$n_{S}^{d}$ and $n_{O}^{d}$ are the numbers of shares and options held by the CEO at the end of the 1999 fiscal year. ExecuComp does not provide details of all option parameters, and we approximate the option portfolios held at the end of 1999 using the algorithm described by Core and Guay (2002a). According to this algorithm, we approximate options granted before 1999 by two hypothetical option grants that are calculated from information on, respectively, exercisable and unexercisable options. We add the options granted in 1999 to these two hypothetical options grants in order to arrive at an estimate of the option portfolio held at the end of the 1999 fiscal year. Then we calculate the exercise price $K$ and the maturity $T$ of a representative option that aggregates the salient features (value and sensitivity to price) of the CEO's option portfolio. We refer the reader to Appendix B for further details. Appendix B also describes the procedure which we used to estimate non-firm wealth from the CEO's past income. ${ }^{21}$ Later we perform robustness checks in order to establish that our results do not depend on potential estimation errors.

From the initial 1,696 CEOs in 2000, we lose 103 CEOs for which necessary data items (stock volatility in 1999 or adjustment factor) are missing, and 886 CEOs due to the required history of at least five years. ${ }^{22}$ The five-year cut-off provides a reasonable balance between the accuracy of our estimates and sample size. ${ }^{23}$ Another 27 CEOs are lost because they were executives in more than one company in at least one year of their history. For the remaining 680 CEOs we estimate their options portfolio and their wealth from the ExecuComp database as described in Appendix B. At this stage, we lose 17 CEOs because of inconsistent or missing data on their option holdings, and 65 CEOs, because our wealth estimate is negative, which can happen if the amounts deducted for the purchase of stock are large. We retain 598 CEOs in our sample that satisfy all our data requirements. 21 CEOs $(3.5 \%)$ have no options in their compensation package while 254 CEOs ( $42 \%$ ) have options on more than $1 \%$ of their company.

[Insert Table 1 about here]

\footnotetext{
${ }^{21}$ The only study we know of that uses an estimate of wealth is Becker (2005), who uses a Swedish dataset based on tax filings. No such information is available for the U.S.

${ }^{22}$ We do not require that the CEOs have been CEO during the entire 5 years. We only require that they were CEO in 2000 .

${ }^{23}$ If we required eight years of continuous history, we would retain only 360 CEOs compared to our current sample of 598. Shortening the length of continuous history in the database required biases our wealth estimates downward. Requiring an eight-year history would increase our median estimate of $W_{0}$ by $27 \%$ (mean: $21 \%$ ). We compensate for this bias with appropriate robustness checks (see Section 6).
} 
Table 1A provides descriptive statistics for the main parameters and Table 1B displays similar statistics for the larger group of executives in the ExecuComp database who were CEO in 2000. We need to adjust the number of options for dividend payments because the CEO receives $n_{O}$ options on a share with end of period value $P_{T} \exp (-d T)$ and $n_{S}$ shares with end of period value $P_{T}$. In order to render our statements on stock holdings and option holdings comparable, we will refer to $n_{S}$ as the number of shares and to $n_{O} \exp (-d T)$ as the number of options. (See also footnote 12 on p. 6 above.) While the CEOs in our sample are similar with respect to the value of their stock holdings, our data requirements have a tendency to exclude CEOs with more options (mean of $1.3 \%$ in the sample, $1.5 \%$ in ExecuComp) and lower salaries (mean of $\$ 2 \mathrm{~m}$ in the sample, $\$ 1.7 \mathrm{~m}$ in ExecuComp). Also, CEOs in our sample are somewhat more experienced (age 57 in our sample, 55 in the database). Finally, note that the stock volatility is lower in our sample (38\%) than in the full ExecuComp database (44\%). In view of our results, the sample is biased in favor of the model: the savings from recontracting predicted by our model are higher for higher volatility, higher option holdings, and for younger, less wealthy CEOs. We would therefore expect even stronger results if we could establish reliable parameter estimates for the larger sample.

\section{Optimal Contracts and Observed Contracts}

We divide our analysis into two parts. In the first part we restrict ourselves to contracts with non-negative option holdings $n_{O}$. We therefore require contracts to be (weakly) convex. This is our benchmark case. In a second step we relax this constraint and allow for negative option holdings by the CEO. We then drop the assumption that contracts are piecewise linear and extend our analysis to more general forms of nonlinearity. Finally, we discuss how our analysis extends to the case with multiple options.

\subsection{Optimal contracts with non-negative option holdings}

Table 2 reports the results for the case where option holdings are restricted to be non-negative. ${ }^{24}$

[Insert Table 2 about here]

\footnotetext{
${ }^{24}$ We solve program (16) and its variants for each CEO in our dataset with the Nelder-Mead simplex method as implemented in SAS Proc IML. We also recomputed our core results with Matlab and did not find any differences beyond numerical accuracy.
} 
Result 1: The model cannot replicate observed option holdings. The first - and probably most surprising - result is that stock options are almost never optimal for plausible levels of risk aversion (see Table 2A). The model predicts positive option holdings only for $1.3 \%$ of all CEOs at $\gamma=3$, and even for extremely low levels of risk aversion this fraction does not rise above $18 \%$ $(\gamma=0.5)$. Moreover, whenever the model does predict options as part of the optimal contract, the fraction of options predicted is miniscule: for $\gamma=3$ optimal option holdings are $0.003 \%$. This represents less than $0.3 \%$ of actual option holdings (compare Table 1). This indicates the complete failure of the model with respect to predicting the option component of observed contracts. Moreover, we only obtain positive option holdings for those cases where the constraint $\phi \geq-W_{0}$ is binding, in all other cases optimal option holdings are always zero. This result is striking and shows that the constraint $n_{O} \geq 0$ is almost always binding to produce a corner solution at $n_{O}=0$.

For low levels of risk aversion we sometimes cannot validate the applicability of the first-order approach. For $\gamma=0.5$ there are 3 CEOs with positive option holdings under the contract that solves (16) where condition (17) is violated. We can always ensure the general validity of the first-order approach for all CEOs and for all values of $\gamma$ equal to 1 or higher.

Result 2: CEOs should hold more stock. Table 2A also shows that stock holdings should be higher. The increase for our base case $(\gamma=3)$ is from an average $2.29 \%$ (see Table 1) to $2.75 \%$, or half a percentage point. It follows directly from the mechanics of the model that lower option holdings are balanced by higher stock holdings in order to maintain incentives. Hence, stock holdings in optimal contracts are uniformly higher, and for any given level of risk aversion the algorithm provides a unique optimal level of stock holdings commensurate with maintaining incentives. Table $2 \mathrm{~A}$ also demonstrates that the number of additional shares required to be held by the CEO decreases markedly as the CEO's risk aversion $\gamma$ increases. This implies that the number of shares given to the CEO to replace one option decreases with risk aversion. As the CEO's risk-aversion rises, stock becomes progressively better at providing incentives because stock also pays off for lower stock prices where marginal utility is comparatively high. Then fewer shares need to be granted to replace one option.

Result 3: CEOs should receive lower base salaries. We can observe from Table $2 \mathrm{~A}$ that mean and median base salaries decline substantially if we compare the base salaries suggested by the model with actual base salaries. If we substitute stock for less valuable options, then the base 
salary needs to decrease so that the CEO's expected utility stays constant and the participation constraint (7) remains binding. Table $2 \mathrm{~A}$ shows that in a large number of cases the CEOs in our sample should have negative base salaries according to the model. If base salaries are negative, then CEOs are required to invest some of their private savings in their company's stock in addition to the stock grants they receive. For $\gamma=3,47 \%$ of CEOs receive no base salary and are required to invest some of their private wealth into their firm.

Note that, as the CEOs risk aversion $\gamma$ increases, the pay cuts suggested by our model decrease substantially. This is an immediate consequence of the fact that the number of shares each CEO receives to replace one option decreases in $\gamma$. Then the cut in base pay necessary to hold her expected utility constant falls as well. In Table 2B we relate the investment into firm stock to the CEO's wealth. While the cut in base salaries appears dramatic, it is moderate compared to most CEOs wealth. For $\gamma=3$, the CEOs invest on average $\$ 2.26 m$ or $10.5 \%$ of their wealth in their firms' stock.

We also investigate how base salaries are correlated with wealth (results not tabulated). The correlation is negative and significant, ranging from -0.51 for $\gamma=0.5$ to -0.20 for $\gamma=10$. This is intuitive as higher wealth leads to lower absolute risk aversion and therefore a higher ratio of shares to be exchanged for one option. Recall that we calculate wealth on the basis of past income (see Appendix B). So, according to the model, some CEOs received too high fixed salaries in the past, leading to a larger accumulation of non-firm wealth. According to the model these contracts need a stronger rebalancing away from options and fixed salary to more stock.

Result 4. Implied savings from optimal contracts are significant. We need to check if the differences between observed and actual contracts are economically significant. We address this issue by comparing the expected costs of total compensation of optimal contracts, $\pi_{0}^{*}$, to the costs of observed compensation contracts, $\pi_{0}^{d}$. Hence $\pi_{0}^{d}-\pi_{0}^{*}$ (expressed as a percentage of $\pi_{0}^{d}$ ) is our measure for evaluating economic significance, which is tabulated in Table 2B.

Based on our model and assuming $\gamma=3,19.6 \%$ of total costs of CEO compensation could be saved on average by moving from observed contracts to the contracts suggested by the model (median 15.6\%). While this number is significant as a proportion of compensation costs as well as in absolute dollar terms $(\$ 12.3 \mathrm{~m}$ (mean), respectively, $\$ 2.4 \mathrm{~m}$ (median) per CEO), the number is not large in relation to the size of most companies. The average savings as a percentage of firm value 
is merely $0.34 \%$. However, we only consider CEOs in our analysis. Since typically the structure of compensation packages is similar for all executives within a single company, the savings would be higher than suggested by Table 2 if companies adjusted the pay structure for all their executives. Altogether we conclude that the difference between observed contracts and contracts generated by the conventional model are statistically and economically significant.

\subsection{Optimal contracts with unrestricted option holdings}

The previous analysis suggests that the non-negativity constraint on options in the optimal contract $\left(n_{O} \geq 0\right)$ is binding in almost all cases. We now replace this constraint with the weaker restriction that the CEO cannot have a short position in options that exceeds her long position in stock: $n_{O} \exp \{-d T\}+n_{S} \geq 0$. This restriction is necessary to guarantee that the CEO's terminal wealth $W_{T}$ is positive in all states of the world. We refer to the contract with this relaxed restriction as the 'unrestricted option contract,' whereas we call the contract with the stronger restriction $n_{O} \geq 0$ 'restricted option contract.' We recompute all our previous results for the unrestricted option contract and present the results in Table 3 .

\section{[Insert Table 3 about here]}

The impact is dramatic. For all CEOs for whom we found zero optimal option holdings in the previous section, we now obtain negative option holdings. At the same time, optimal stock holdings almost double from $2.75 \%$ to $5.33 \%(\gamma=3)$. The resulting contract is now concave for $98.7 \%$ of all CEOs. Pay for performance-sensitivity for low stock prices (below the strike price of the option) is significantly higher because of the higher stock component. For stock prices above the strike price of the option, pay for performance-sensitivity is miniscule. For a large number of CEOs, pay for performance sensitivity is zero for higher stock prices. In these cases, the number of options just offsets the number of shares. Average base salaries are lower $(-\$ 16.6 \mathrm{~m}$ instead of $-\$ 1.65 \mathrm{~m}$ for $\gamma=3$ ) and the proportion of wealth that CEOs would need to invest in their companies' stock is also much higher (47.5\% instead of $10.5 \%)$. The unrestricted contract also generates much higher savings (36.5\% instead of $19.6 \%$ before). We therefore conclude that our model implies that optimal contracts are concave except in very few cases. 


\subsection{General nonlinear contracts}

In order to understand why the optimal contract features negative option holdings for most CEOs, we now consider contracts where we do not restrict the nonlinearity to piecewise linear contracts. Instead we now analyze the solution to the optimal contracting problem (6) - (10) for a general function $\pi\left(P_{T}\right)$ that is not constrained to be implemented with stock and options. In Appendix A.1 we derive the following solution for $\pi\left(P_{T}\right)$, where $\alpha_{1}>0$ and $\alpha_{0}$ are parameters that depend on the production function $P_{0}(e)$ and the Lagrange multipliers on the constraints $(7)$ and $(8)$ :

$$
\pi\left(P_{T}\right)=\left\{\begin{array}{ccc}
\left(\alpha_{0}+\alpha_{1} \ln P_{T}\right)^{1 / \gamma}-W_{0} \exp \left(r_{f} T\right) & \text { if } \quad P_{T} \geq \bar{P} \\
-W_{0} \exp \left(r_{f} T\right)+\varepsilon & \text { if } \quad P_{T}<\bar{P}
\end{array},\right.
$$

where $\bar{P}=\exp \left(\left(\varepsilon^{\gamma}-\alpha_{0}\right) / \alpha_{1}\right)$ and the constant $\varepsilon$ is the minimum level of wealth that must be left to the CEO in all states of the world. This ensures that the argument of the utility function is bounded away from zero so that utility is bounded away from minus infinity. In Appendix A.1 we also show that the optimal contract is concave for all prices $P_{T}$ above a certain threshold that exceeds $\bar{P}$ for $\gamma<1$ and equals $\bar{P}$ for $\gamma \geq 1$. For $\gamma<1$, the function is convex for a range above $\bar{P}$. In all cases the function is locally convex at $\bar{P}$. We will refer to the contract with the pay function (18) as the 'general nonlinear contract.'

The fact that the optimal general nonlinear contract features a convex region holds out the promise that we did not detect the potential usefulness of options because contracts with only one option may be ill-suited to approximate a nonlinear function with convex and concave regions. Clearly, the $\pi\left(P_{T}\right)$-function (18) is not implementable with shares and options, although it can be approximated arbitrarily well with a sufficiently large number of call and put options with different strike prices. ${ }^{25}$ We can still estimate optimal contracts like (18) using our methodology by simply optimizing over the free parameters $\alpha_{0}, \alpha_{1}$, and $\varepsilon$ without parameterizing the full model. ${ }^{26}$ In particular, we can do so without specifying the production function $P_{0}(e)$, the CEO's cost function $C(e)$, or the Lagrange multipliers on (7) and (8). Figure 1 shows the results for one representative CEO and Table 4 tabulates the results for the entire sample. ${ }^{27}$

\footnotetext{
${ }^{25}$ Related claims can be found in Ross (1976) and Farmer and Winter (1986).

${ }^{26}$ For numerical reasons, we restrict the CEO's minimum terminal wealth $\varepsilon$ by $\varepsilon \geq P_{0} / 100,000$. When we relax this restriction, the algorithm becomes unstable. In Table 4, the numerical problems of relaxing this constraint become apparent for $\gamma=10$, where we lose $52 \%$ of the CEOs because the algorithm did not converge. The only notable effect of relaxing this constraint is that the threshold $\bar{P} / P_{0}$ in Table 4 gets even smaller and that average savings slightly increase.

${ }^{27}$ We note that the validity of the first-order approach for the general non-linear contract is assured by Jewitt
} 


\section{[Insert Table 4 about here]}

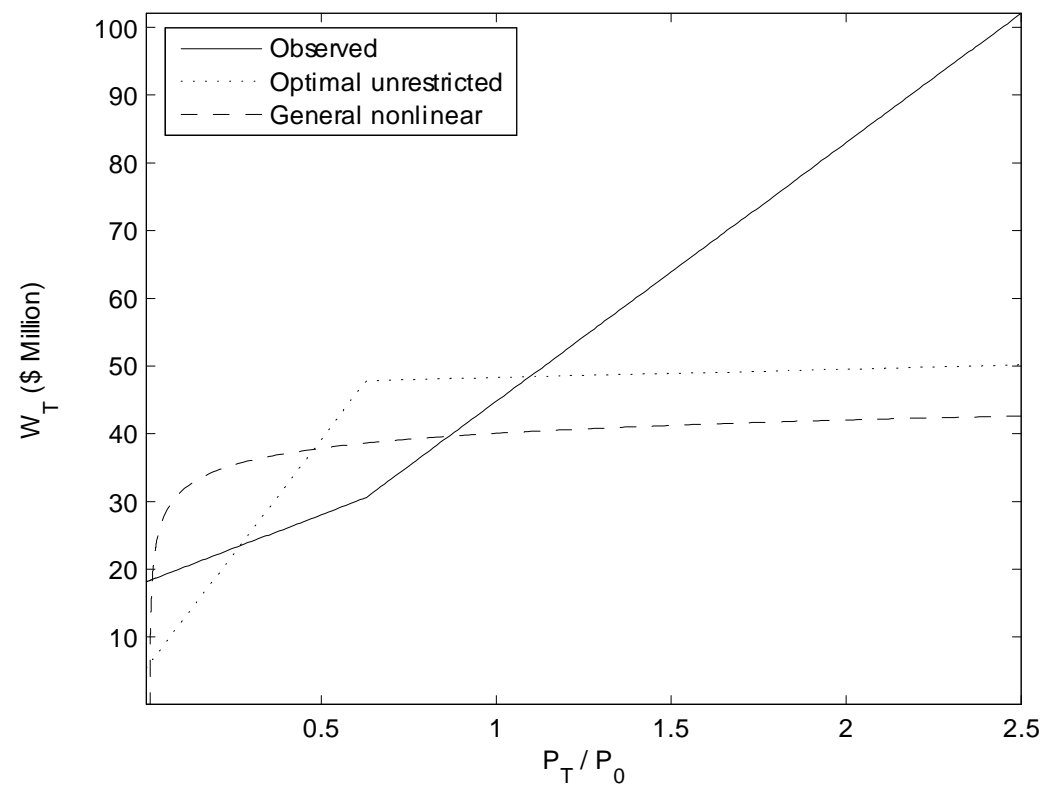

Figure 1: The figure shows end of period wealth $W_{T}$ for the observed contract (solid line), the optimal unrestricted option contract (dotted line) and the optimal general nonlinear contract (dashed line) for one representative $\mathrm{CEO}$ whose parameters are close to the median of the sample. The parameters are $\phi=\$ 1,2 \mathrm{~m}, n_{S}=0.42 \%, n_{O}=0.50 \%$ for the observed contract. Initial non-firm wealth is $W_{0}=\$ 9.1 \mathrm{~m}$. $P_{0}$ is $\$ 3.70$ bn and $K / P_{0}$ is $63 \%, T=8.5$ years, $r_{f}=6.6 \%, d=2.3 \%$. All calculations are for $\gamma=3$.

The figure shows alternative contracts for one CEO with $\gamma=3$ who is representative of the sample. It shows the observed contract with one representative option, the unrestricted option contract and the general nonlinear contract. The horizontal axis in the figure is scaled by the current stock price, so that 1 corresponds to a terminal stock price $P_{T}$ equal to the current price. The general nonlinear contract is highly concave with an enormous slope for low terminal stock prices (below 10\%-20\% of the current price). We characterize the function in Table 4 by reporting the average cut-off price $\bar{P}$ from (18) as a percentage of the current stock price. Evidently, this cutoff is very small $\left(0.5 \%-4.2 \%\right.$ of the current stock price) for moderate levels of risk aversion. ${ }^{28}$ Hence, the point of the local convexity of the optimal contract is in a region of very low (and hence unlikely) stock prices.

(1988).

${ }^{28}$ The comparatively high values of $\bar{P} / P_{0}$ for $\gamma=1$ are due to the fact that the utility function is not continuous in $\gamma$ at $\gamma=1$. We expect that this effect would disappear if we could calculate optimal contracts for the related version of the utility function (see footnote 14) that is continuous in $\gamma$ at $\gamma=1$. 
We report the slope of the contract by looking at changes in wealth if the standard normal random variable $u$ in (1) changes from its expected value 0 to $-1,-4,+1$, or +4 . For example, for $\gamma=3$, if $u=+1$ (one standard deviation above its mean), then wealth increases by $5.9 \%$ for the optimal contract, whereas the same number is $107.4 \%$ for the actual contract. For $u=-1$, the change is $-6.7 \%$ for the optimal contract and $-27.4 \%$ for the actual contract. Hence, for $\gamma=3$, the \pm 1 standard deviation range exhibits a lower pay for performance sensitivity than the observed contract and this difference becomes more pronounced as risk aversion increases. We can also measure the concavity of the optimal general nonlinear contract by the fact that a one standard deviation decrease in $u$ is accompanied by a larger absolute change in wealth $(-6.7 \%)$ compared to a one standard deviation increase of $u(5.9 \%)$. The opposite is true for the observed contract, where the decline $(-27.36 \%)$ is much smaller than the corresponding increase $(107.4 \%)$. For low levels of risk aversion the optimal contract includes large penalties for extreme underperformance: basically, the CEO loses more than $99 \%$ of her wealth if $u$ falls more than 4 standard deviations below its expected value, an event that has a probability of $0.0032 \%$.

Overall, we can observe that the optimal general nonlinear contract differs from the observed contract not only quantitatively but also qualitatively. The observed contracts essentially rely on "carrots" where the CEO receives large benefits from performing above expectations and suffers limited penalties for underperformance. By comparison, the optimal general nonlinear contract relies on "sticks" and the CEO receives only a comparatively small increase in wealth for outperforming expectations, but suffers severe penalties from extreme underperformance.

The piecewise linear contract that can be implemented with one option tries to approximate the optimal general nonlinear contract. We can gauge the quality of this approximation by comparing the savings implied by these contracts. These are $45.2 \%$ for general nonlinear contracts and $36.5 \%$ for unrestricted option contracts.

We could approximate the general nonlinear contract in Figure 1 with stock and with short positions in several call options with different strike prices. By appropriately increasing the number of different strike prices in the option portfolio we could approximate the optimal general nonlinear contract $\pi^{*}\left(P_{T}\right)$ arbitrarily well. Then the positions in all options except the one with the lowest strike price would be short positions. We analyzed the case with stock and two options, where we fixed strike prices at $25 \%$ and $50 \%$ of today's price. We found that savings from such a contract are $39.0 \%$ (results not tabulated) and therefore higher than those for unrestricted option contracts 
(36.5\%, see Table 3), restricted option contracts (19.6\%, see Table 2), but lower than those from general nonlinear contracts $(45.2 \%$, see Table 4$)$. The contracts suggested by such a model exhibit even higher stock holdings compared to the model with only one option, with correspondingly more negative positions in options. However, all other qualitative features are the same as those of the model with one option only, so we do not discuss them here in more detail.

\section{$5 \quad$ Investment incentives and optimal contracts}

The discussion of the previous section leads us to the conclusion that long positions in options are rarely part of an optimal contract. In this subsection we investigate another explanation for the use of stock options that was first formulated by Smith and Stulz (1985) and emphasizes the fact that options provide incentives for managers to invest in risky projects. Indirect evidence in support of this notion was found by a number of studies. ${ }^{29}$ We approach this question from the perspective of our model as follows. A CEO would be deterred from investing in a positive NPV project if the project increases the risk of the company and her utility decreases in the volatility of the company, so that $\frac{\partial E U}{\partial \sigma}<0$. Hence, we compute this derivative and determine by how much the CEO's utility would fall from an increase in volatility by 1 percentage point (e. g., from 0.30 to 0.31) and compare this change in utility between the observed contract and the optimal contract prescribed by the model. ${ }^{30}$ Table 5 summarizes our results.

[Insert Table 5 about here]

For example, for $\gamma=3$, utility decreases on average by $2.51 \%$ from a 1 percentage point increase in volatility under the observed contract, by $3.00 \%$ under the optimal restricted contract, and by $4.42 \%$ with the optimal unrestricted contract. By comparison, the decline in utility is $18.37 \%$ under the optimal general nonlinear contract, which is therefore significantly more concave.

In Table 5B we provide another approach to the same data. Here, we define a CEO as riskaverse if her utility declines by more than $1 \%$ from a 1 percentage point increase in volatility, and

\footnotetext{
${ }^{29}$ Williams and Rao (2000) show that CEOs with more stock options tend to undertake risk-increasing acquisitions. Tufano (1996) shows that companies in the gold mining industry hedge more if their executives own more stock and less if they hold more options. Guay (1999) provides evidence that companies with more growth opportunities provide their executives with more incentives to take risks. Rajgopal and Shevlin (2002) find that stock options increase the inclination to take risks in a study of oil and gas producers. Similarly, Li (2002) presents evidence consistent with the view that companies continuously adjust the contracts of their CEOs if they deviate from contracts that provide optimal risk-taking incentives.

${ }^{30}$ Guay (1999) analyzes sensitivies of wealth to risk by looking at $1 \%$-changes in $\sigma$.
} 
as risk-neutral if her utility declines by less than $1 \%$. With this definition of risk aversion and risk neutrality, and for $\gamma=3,26.3 \%$ of all CEOs are classified as risk-neutral under the observed contract, compared to $18.6 \%$ under the optimal restricted contract, and $8.7 \%$ under the optimal unrestricted option contract. This percentage drops to a mere $1.3 \%$ under the general nonlinear contract. We also applied other cutoffs for separating risk-neutral from risk-averse CEOs. With a $0.1 \%$ decline in utility as a cut-off, $95.3 \%$ of CEOs would be classified as risk-averse under the observed contract, a proportion that increases to $99.5 \%$ and $100 \%$ under the restricted option contract and the two concave contracts $(\gamma=3)$.

We interpret these results as saying that observed contracts normally do not change the CEO's attitude towards risk appreciably in one way or another compared to optimal restricted contracts. The proportion of CEO's whose risk-aversion is practically neutralized by their option holdings (so that $\left.\frac{\partial E U}{\partial \sigma} \approx 0\right)$ is small, no matter which definition of "practically neutralized" we apply. Even compared to optimal unrestricted contracts - which are concave for most CEOs - the difference is very moderate. The picture is very different only for the general nonlinear contract (18) that may carry a serious risk of underinvestment in risky projects. For this contract, the distortion of risk aversion as shown in Table 5 is more substantial and the fraction of CEOs classified as "riskneutral" is significantly smaller. We conclude that the use of stock options to create risk-taking incentives might explain why we do not observe general nonlinear contracts, but this argument does not appear strong enough to explain why observed contracts are convex instead of linear. ${ }^{31}$

\section{Robustness Checks}

In this section we discuss some of the assumptions made above in order to assess the robustness of our conclusions presented so far. As a benchmark we choose the model with restricted option contracts. While unrestricted option contracts or general nonlinear contracts generate higher savings, they seem less realistic. Firstly, negative options holdings are never used. Secondly, concave payoffs are unsuitable for providing risk-taking incentives as demonstrated in the last section. Finally, the implied investments in company stock compared to CEO wealth seem unrealistically large (47.5\% for unrestricted option contracts compared to $10.5 \%$ for restricted option contracts; compare Tables 2 and 3). We therefore hold that restricted option contracts provide the most realistic alternative

\footnotetext{
${ }^{31}$ Other authors have also expressed scepticism on the view that options uniformly increase risk-taking incentives, see e. g. Carpenter (2000) and Ross (2004).
} 
to observed contracts.

\subsection{Measurement of Wealth}

The variable measured with the least accuracy in our data is certainly initial non-firm wealth $W_{0}$. In order to establish how sensitive our results are to errors in initial wealth, we multiply our wealth estimates by a multiplier $M_{W}$ and compute optimal contracts assuming $\gamma=3$. Results for other levels of risk aversion are qualitatively similar. We consider multipliers $M_{W}$ in the range from 0.1 to 5. The main results are summarized in Figure 2. The main observations from the figure are
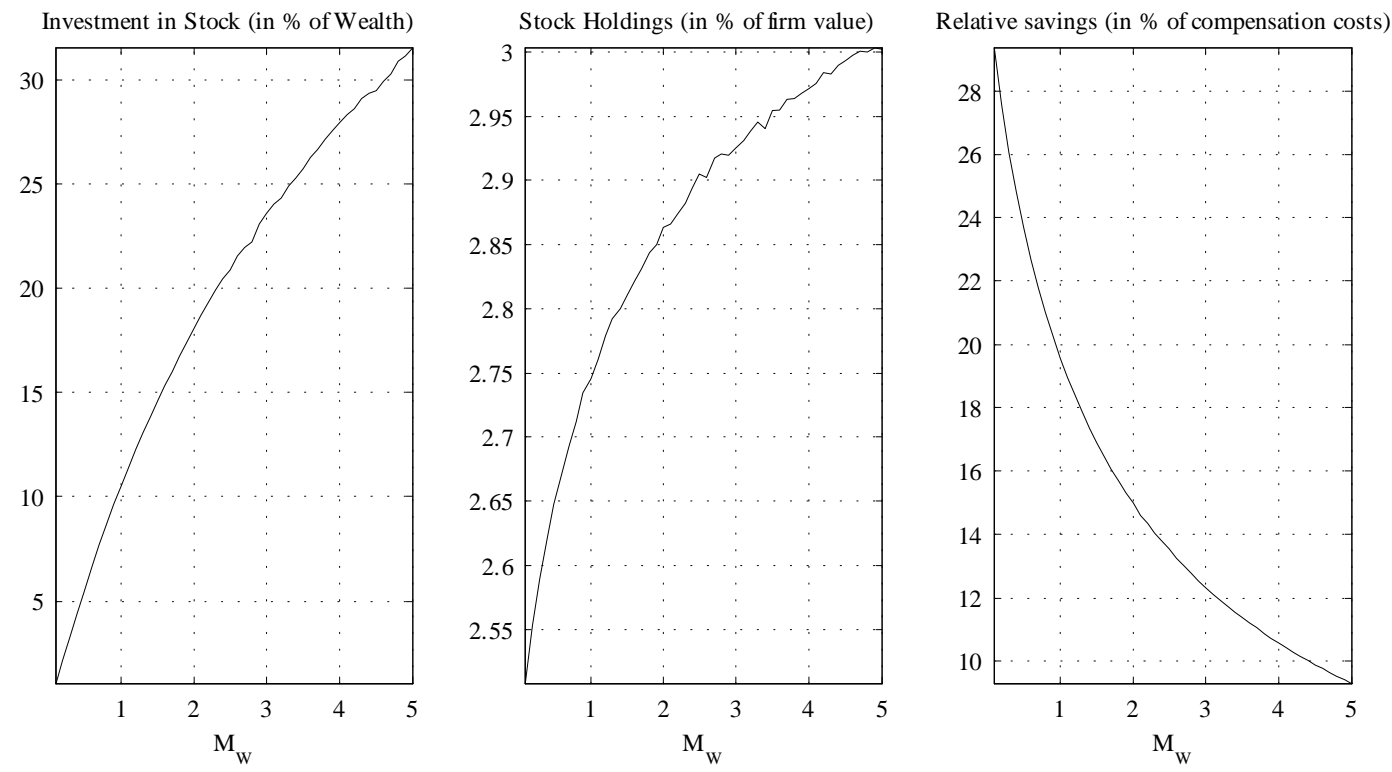

Figure 2: Comparative statics for wealth. We vary our measure of wealth by multiplying $W_{0}$ for each CEO by a constant factor $M_{W}$ between 0.1 and 5. All calculations are for $\gamma=3$. For the base case, investment in stock relative to wealth and relative savings are reported in Table $2 \mathrm{~B}$, stock holdings in Table 2A.

that (i) investment in stock as a percentage of wealth will increase in wealth (i. e., as a function of $M_{W}$ ), (ii) stock holdings will increase in wealth, and (iii) savings from recontracting are a declining function of wealth. On the whole we observe what we would expect as a result of constant relative risk aversion, where absolute risk aversion falls as wealth increases. The effect of an increase in wealth is therefore the same as the effect of a fall in risk aversion, which was amply documented in Tables 2 - 5. Hence, none of our qualitative conclusions is affected and the comparative static properties of the model are very regular. 


\subsection{Measuring the convexity of contracts}

Our analysis relies only on shares and stock options to measure pay for performance sensitivity. By comparison, Jensen and Murphy (1990) also consider the incentives generated by bonus payments and CEO dismissals as part of their measure of performance sensitivity. Of particular concern for our analysis is the potentially incorrect measurement of the convexity of observed contracts. We address these shortcomings here.

We run conventional logit regressions for CEO dismissals (see Brickley, 2003, for a brief summary of the literature on CEO turnover). The dummy variable for dismissal equals one if a CEO who is in the database in 1995 is recorded as "resigned" in one of the subsequent five years. We regress this dummy variable on the five-year abnormal stock return from 1995-2000. We then use this parameterization of the logistic function to establish the probability of firing the CEO as a function of the stock return $p\left(P_{T} / P_{0}\right)$ and redefine end of period wealth as a function of terminal stock prices (compare (2)) as:

$$
W_{T}=W_{0} \exp \left\{r_{f} T\right\}+\left(1-p\left(P_{T} / P_{0}\right)\right)\left[\phi \exp \left\{r_{f} T\right\}+n_{S} P_{T}(u, e)+n_{O} \max \left\{P_{T}(u, e)-K, 0\right\}\right]
$$

Similar to Jensen and Murphy (1990) we assume that the CEO loses all her compensation in case of dismissal, which is most likely an overstatement as it ignores severance pay. We then recompute the utility adjusted pay for performance sensitivity using (19) instead of (2). The results are shown in Table 6.

[Insert Table 6 about here]

Table 6 reveals that UPPS increases for high levels of risk aversion, but decreases for small levels of risk aversion. The reason is that dismissals affect performance sensitivity in two ways. First, the potential loss of all future compensation payments increases UPPS because an upward shift in the mean of the distribution reduces the CEO's risk of being fired. However, with a probability $p\left(P_{T} / P_{0}\right)$ the CEO loses all her performance-related pay, so conditional on being fired the CEO's payoff is now independent of her performance, which reduces incentives. The weight on the two effects depends on the CEO's utility function and the higher her risk aversion, the more important is the first effect and the less important is the second effect.

We also measure the convexity of contracts directly. Observed contracts are piecewise linear, so 
we cannot use second order derivatives to analyze convexity. Instead, we use a discrete approach and measure the difference in slopes of $W_{T}$ with respect to $P_{T}$ from (2) and from (19) around the strike price of the option. ${ }^{32}$ For (2) the change in slope is simply $n_{O}$ (the slope changes from $n_{S}$ to $\left.n_{S}+n_{O}\right)$. We calculate this change in slope for (19) and find that for 494 CEOs, dismissals reduce the convexity of the $W_{T}$-function, whereas the convexity increases for 104 of the CEOs in our sample. 11 contracts become concave. (Results are not reported in the tables.) For the median CEO, dismissals reduce the convexity of the $W_{T}$-function by $4.86 \%$, i.e. the change in slope is $0.951 n_{O}$ in the model with dismissals compared to $n_{O}$ without dismissals, so the difference is economically negligible.

We also looked at bonus payments and tested if their sensitivity to stock price increases is higher for high stock prices than for low prices. We found that bonus and salary changes make the contracts more convex, although this effect is mostly statistically insignificant.

We conclude that we measure the convexity of contracts correctly on average, even though there is some cross-sectional variation arising from CEO turnover and changes in salaries that we left out before. We note that our approach has the additional advantage that it uses only CEOspecific variables and does not impose parameters from cross-sectional regressions based on the whole sample on individual CEOs.

\subsection{Alternative Technologies}

The choice of the lognormal distribution, which has become standard for many applications may bias the results against options. Hemmer, Kim, and Verrecchia (2000) suggest the Gamma distribution as an alternative model for the technology in a principal agent model and show that it can generate convex contracts for $\gamma=0.5$. We therefore repeat our analysis and replace the lognormal distribution with the Gamma distribution and calibrate the distribution again to match the first two moments (market capitalization and standard deviation of returns). Table 7 summarizes the main results.

\section{[Insert Table 7 about here]}

\footnotetext{
${ }^{32}$ More precisely, we measure the difference in slopes of $W_{T}$ between $u(K)+1$ and $u(K)-1$, where $P(u(K))=K$ (see equation $(1))$.
} 
We confirm the result of Hemmer, Kim, and Verrecchia (2000): for $\gamma=0.5$, we obtain significant option holdings for all CEO's. ${ }^{33}$ However, for larger values of risk aversion the differences between the lognormal distribution and the Gamma distribution become small, and for $\gamma \geq 4$ implied savings are on average larger with the Gamma model than with the lognormal model. For reasons discussed above, we do not believe the region below $\gamma=1$ to be particularly relevant and conclude that this approach does not lead to a substantially more realistic model.

\subsection{Market Risk and Firm-Specific Risk}

In the discussion of our valuation approach above we briefly hinted at the fact that our approach may overstate the riskiness of options to the CEO as she could eliminate the market component of this risk by trading in the market index, an aspect not included in our model. We check for the importance of the distinction between firm-specific risk and market risk as follows. We estimate firm-specific risk $\sigma_{\varepsilon}^{2}$ by using the relationship $\sigma_{\varepsilon}^{2}=\sigma^{2}-\beta^{2} \sigma_{M}^{2}$, where $\sigma_{M}^{2}$ represents the volatility of the market and $\beta$ the CAPM-beta. We assume $\beta=1$ for all companies in our sample and estimate $\sigma_{M}=0.17$ for the year 2000. Then we numerically recalculate all contracts with $\sigma_{\varepsilon}^{2}$ instead of $\sigma^{2}$. However, we still use total risk $\sigma^{2}$ in order to calculate the costs of options to the company. We do not tabulate the results as they are similar to those reported above and none of the qualitative results is affected. Ultimately, a completely satisfactory analysis of firm-specific and systematic risk must rest on a more complete model that explicitly models investments in the stock market. Existing research based on numerical examples is consistent with our findings. ${ }^{34}$

\section{$7 \quad$ Interpretations and Extensions}

The results from Section 4 leave us with the robust conclusion that observed practice does not conform to the predictions of our model. In this section we investigate if appropriate modifications of our model would generate observed contracts as results of efficient contracting.

\footnotetext{
${ }^{33}$ This leads also to a violation of the sufficient conditions for the validity of the first-order approach in a large number of cases. Hence, for low values of $\gamma$ this analysis is valid only if we are also prepared to assume conditions stronger than just concavity of the production function and convexity of the cost function.

${ }^{34}$ See Jenter (2002), Ingersoll (2002) and Cai and Vijh (2005).
} 


\subsection{Incorporating Taxes}

So far our analysis ignores taxes. The optimal contracts calculated from our model suggest that CEOs should receive no options, lower base salaries, and more restricted stock. In this subsection we investigate the impact of taxes on our analysis. We differentiate between personal and corporate taxes. We carefully distinguish between restricted stock awarded by the company to the CEO and unrestricted stock that the CEO either held previously or that she bought from her own funds at the beginning of the contract period $(t=0)$. More specifically, we make the following assumptions: ${ }^{35}$

Base salary. The fixed component $\phi$ of compensation is paid at time $t=0$ and is fully taxed at the personal level. For tax purposes it is regarded as a bonus and is therefore tax deductible at the corporate level. However, if $\phi<0$, then neither the company nor the CEO receives a tax credit as we treat this as a purchase of unrestricted stock by the CEO.

Stock option grants. Stock options are exercised at time $t=T$. At this point in time, the gain from exercising the options, $P_{T}-K$, is taxed at the personal level and creates a deductible expense for the company.

Restricted stock grants and unrestricted stock. Restricted stock may or may not be tax deductible at the corporate level. Tax law allows expensing of restricted stock and base salary up to a total of $\$ 1$ million. Also, restricted stock can be expensed if it is awarded as part of a shareholder approved incentive plan. We assume that this is always the case and treat restricted stock as a tax deductible expense for the company at the end of the vesting period. At the personal level, the CEO defers taxes on the grant until the time when vesting lapses and we assume that this is the end of the contract period, $t=T$ on the value $P_{T}$ per share. Unrestricted stock is a purchase by the CEO from after-tax income and has no tax consequences other than taxes on dividends and capital gains.

Dividends and capital gains. Dividends are taxed at the personal level at the time of payment. We assume that the after tax dividend is reinvested in the company's stock. Capital gains can be deferred indefinitely and are never taxed.

\footnotetext{
${ }^{35}$ The analysis is based on Hall and Liebman (2000). The precise analysis of taxes is somewhat tedious. We have prepared a short technical document that reparameterizes our model in order to allow for taxes along the lines described in the text. This document is available from the authors upon request.
} 
We use a tax rate of $42 \%$ for personal taxes and a rate of $35 \%$ for corporate taxes.

[Insert Table 8 about here]

Table 8 displays the results for the optimal restricted option contract. We now obtain larger option holdings compared to the case without tax effects (cf. $n_{O}^{*}=0.003 \%$ in Table 2 to $0.028 \%$ in Table 8 for $\gamma=3$ ). However, while the relative increase is substantial, the absolute increase is marginal. The number of contracts with positive option holdings increases from $1.3 \%$ to $9.6 \%$ of all CEOs. The favorable tax treatment of options also reduces the benefits to the company from $19.6 \%$ of total pay (cf. Table 2B) to $13.4 \%$ of total pay. The number of CEOs for whom we cannot verify the validity of the first-order approach increases somewhat relative to the case without taxes. For realistic levels of risk aversion, this affects less than $10 \%$ of our sample. We conclude that tax effects explain a small part of the use of stock options for a small number of CEOs, but the effect is not nearly sufficient to explain observed compensation practice.

\subsection{Sticky base salaries.}

A simple way to fix our model would be to introduce a sticky base salary constraint. Assume that CEOs' base salaries cannot be cut below a certain threshold value, and that this value coincides with the observed base salary, so we would add the constraint $\phi \geq \phi^{d}$ to program (16). Then we would find immediately that all contracts are rationalized as optimal contracts of this modified program. To see this, recall that our model trades off a combination of options and base salary against stock. Rebalancing the portfolio towards fewer options and more stock is feasible only if we can reduce base salaries at the same time, we cannot just shift between stock and options. Mathematically, adding the minimum salary constraint leads to a program where the solution is already determined by the constraints, so no further optimization is possible.

Note that a lower bound on base salaries and the participation constraint cannot bind at the same time. A binding downwards constraint on salaries therefore implies that the participation constraint (7) is not binding, so that the solution is defined by the incentive compatibility constraint (8). If we add one stock option to the CEO's compensation package, then this increases compensation costs by the Black-Scholes value $B S$ and the pay for performance sensitivity by the option delta $N\left(d_{1}\right)<1$. Hence, the price per unit of incentives is $B S / N\left(d_{1}\right)$. The delta of a share is 1 and it costs $P_{0}$. Hence, stock options are always cheaper in providing incentives as 
$B S / N\left(d_{1}\right)<P_{0}$. Delta may be adjusted to allow for risk aversion and exposure to firm-specific risk. This argument is correct if we ask: what is the best form to provide incentives, holding base salary constant? In a model like ours where base salaries can vary, the comparison of dollar costs of pay for performance sensitivity is irrelevant: then we must compare the CEO's risk premiums for options and for stock. This analysis also sheds some light on the small fraction of CEOs with positive option holdings discovered before $(1.3 \%$ for $\gamma=3$, see Tables 2,3$)$. These CEOs have very little wealth and not all of their option holdings can be replaced with stock without violating the constraint that $\phi+W_{0} \geq 0 .{ }^{36}$

One plausible economic reason for sticky CEO base salaries are liquidity constraints: if the CEO demands some compensation to finance consumption today because she cannot borrow against future compensation, then she will not accept a contract that offers more deferred compensation in exchange for a lower base salary. If this liquidity hypothesis were the correct explanation of the usage of stock options, then we should observe more options in the compensation packages of those CEOs who have lower wealth, other things being equal. Also, CEOs of larger firms should find it more difficult to purchase additional stock to provide significant incentives. Table 9 investigates if these predictions are borne out by the data. The dependent variable is the proportion of options in the risk-neutral pay for performance sensitivity, defined as:

$$
\text { Proportion of options }=\frac{n_{O} N\left(d_{1}\right)}{n_{O} N\left(d_{1}\right)+n_{S}} .
$$

[Insert Table 9 about here]

Initial wealth and firm size (measured by the log of market capitalization) both have a highly significant effect on the proportion of options. As expected, the effect of initial wealth is negative and the effect of firm size is positive. Even though the slope estimates are highly significant, the economic effects are rather small, even after controlling for volatility (cf. regression (4)): doubling a CEO's wealth decreases the proportion of options in her incentive pay by only about 5.9 percentage points. Similarly, doubling the market capitalization of her company increases her proportion of options by about 4.2 percentage points. Also, the adjusted R-squared is only $14 \%$ and a large part of the variation in the proportion of options remains unexplained. Our dataset contains some very

\footnotetext{
${ }^{36}$ It seems that the imposition of a more stringent limited liability constraint also explains most of the apparent difference between Lambert and Larcker's (2004) results and ours. They also make somewhat different parametric assumptions and allow the level of incentives to vary in their example. We suspect that loosening the limited liability constraint in their analysis would dramatically reduce the optimal option holdings they find.
} 
wealthy CEOs who hold options (e. g. Michael Dell), and it seems implausible that they could be liquidity-constrained. Also companies might underwrite a loan and thereby help to overcome liquidity constraints. Hence, the liquidity hypothesis remains somewhat unconvincing and cannot explain most of the variation in the data.

We also suspect that liquidity constraints are stronger for younger CEOs and those who have joined the company more recently. With increasing age and tenure, CEOs would then successively exercise options and hold more stock of the company. This hypothesis is borne out by the data (see regressions (5) - (7) in Table 9), but again, the quantitative impact is small: an increase in tenure of 1 year reduces the proportion of options by $0.7 \%$, so a CEO who has been with the firm for 10 years has on average $7 \%$ less of her incentive pay in options compared to a CEO who has just joined. Table 9 is also useful for comparing our methodology with regression analysis: all variables in Table 9 are significant and have the predicted signs. This indicates that the model's qualitative implications are correct, even though the quantitative implications do not get close to matching the data.

\section{Discussion and Conclusion}

We analyze executive compensation contracts using a standard, one-period principal agent model of efficient contracting with CRRA-utility and lognormal distribution of stock prices and estimate it for a sample of 598 US CEOs. Our assumptions are widely used in the compensation literature, but the model yields predictions that markedly differ from observed compensation schemes. Generally, the model predicts that optimal compensation schemes should have no or at best miniscule holdings of stock options, and that incentives should be provided through restricted stock. In addition, base salaries should be lower, and many CEOs would be required to invest some of their savings into their company's stock. By switching from observed contracts to optimal contracts, companies could realize economically significant savings. These results are robust to several model variations and extensions. We therefore feel compelled to conclude that neither the conventional model nor any of its obvious extensions or modifications explain the pervasive practice of awarding stock options to CEOs. The economic significance of our results may be exaggerated quantitatively by using data from the year 2000, which saw a peak in option compensation. ${ }^{37}$ We would therefore expect

\footnotetext{
${ }^{37}$ Towers Perrin (2004) reported in 2004 that " (...) run rates have decreased over the past three years as companies have begun to shift their equity compensation from primarily stock options to more full-value shares."
} 
that using more recent data would change our numbers, however, without influencing our general, qualitative conclusions.

There are two alternative ways to interpret these results. One possibility is to conclude that CEO compensation does not follow the efficient contracting paradigm and that CEOs use options as a vehicle to extract rents from shareholders. This view coincides with the popular argument that options are a form of hidden compensation that is not fully perceived by the market, as expressed by managers' resistance to the expensing of employee stock options (see Dechow, Hutton, and Sloan, 1996). ${ }^{38,39}$ We therefore also considered the hypothesis that potential savings from switching to the optimal contract are higher in firms with weak corporate governance. We conducted a rather preliminary analysis and found mixed support for this hypothesis. We do not report our results as this discussion clearly extends beyond the scope of our paper and should be the subject of further research. Our main contribution to this literature is our savings variable that can be interpreted as a measure of contractual inefficiency. If the inefficient contracting view is correct, then our measure of contracting inefficiency should be related to measures of effective corporate governance. ${ }^{40}$

The alternative conclusion is to reject our model and to search for alternative models that can better explain observed compensation practice. We consider three different model extensions in this paper. While none of them can individually explain a substantial part of observed option holdings, they may be part of a more complex explanation:

- Options may be awarded to provide incentives to invest in risky projects rather than (or in addition to) effort incentives. We show that this argument rules out concave contracts. Concave contracts lead to even higher savings than the linear 'no options' contract in our modelling framework, but they severely reduce CEOs' investment incentives. On the other hand, the linear 'no options' contract reduces the incentives to invest only slightly, so this argument seems unable to explain why so many compensation packages contain stock options.

- Taxes favor options, and we show that predicted option holdings increase markedly when

\footnotetext{
${ }^{38}$ Guay, Kothari, and Sloan (2003) hold against this that the costs of stock options are much larger than could be justified by revealed preferences to report higher earnings.

${ }^{39} \mathrm{It}$ is difficult to reconcile the inefficient contracting view with other evidence in the literature. See Core, Holthausen, and Larcker (1999), Himmelberg, Hubbard, and Palia (1999), and Bertrand and Mullainathan (2000) for evidence on systematic variations between economic variables and CEO compensation that corroborates efficient contracting models. Kedia and Mozumdar (2002) and Hanlon, Shevlin and Rajgopal (2003) find evidence for the performance impact of stock options. The latter study concludes that there is little evidence for rent extraction.

${ }^{40}$ To facilitate future research on this issue, we provide our savings variable for each CEO for a number of years on www.wiwi.hu-berlin.de/...
} 
personal and corporate taxes are taken into account. Still, predicted and observed option holdings differ by several orders of magnitude.

- If CEOs are liquidity constrained, then their base salaries cannot decrease and observed option holdings are automatically optimal. Our regression results provide only limited support for the hypothesis that CEOs are liquidity constrained. Nevertheless, liquidity constraints might explain observed option holdings for a few young and relatively poor CEOs. ${ }^{41}$

A number of further explanations for the use of stock options have been put forward in the literature and might turn out to be successful in aligning theory and compensation practice. Oyer and Schaefer (2005) suggest that CEOs may be overconfident or overly optimistic about the future development of the stock of their companies. We actually replicated their results and found qualitatively very similar conclusions, namely only very moderate increases in option holdings. Holmström and Ricarti Costa (1986) and Nohel and Todd (2005) consider career concerns, Jost and Wolff (2003) model preferences based on loss aversion rather than expected utility, Oyer (2004) analyzes employee retention, and Inderst and Müller (2003) discuss incentives to make optimal liquidation decisions. Behavioral biases like valuation errors in capital markets may also account for the widespread use of options: Garvey and Milbourn (2002) show for instance that stock markets underestimate the dilution effect of stock options. Also, the use of stock options could possibly be better explained in adverse selection models instead of the effort aversion approach followed in this paper. Dybvig and Zender (1991) show for instance that contracts based on fixed salaries and (restricted) stock alone cannot prevent the CEO from making inefficient investment decisions. Another avenue for further research may be the explicit consideration of the dynamic aspects of contract negotiation. The standard model and its variants discussed in this paper are static and as a result any empirical implementation ignores the fact that contracts are adjusted every year and that the structure of contracts today determines the positions of each party in future negotiations.

We regard the search for a parsimonious model that explains existing compensation practice as an important task for future research. This model should provide a more satisfactory answer to questions of optimal option design (such as reloading, repricing, indexing, or strike prices) that have so far been analyzed in the context of a model that is unable to generate optimal contracts with options.

\footnotetext{
${ }^{41}$ See Kedia and Mozumdar (2002) for the argument that options help to overcome liquidity constraints at the firm level.
} 


\section{Appendix}

\section{A Theoretical Analysis}

\section{A.1 Solving for the General Contract}

In this appendix we discuss a more general contract that can be written as a general pay-function $\pi\left(P_{T}\right)$, which denotes the compensation the manager receives at time $T$. From (1), $P_{T}$ is distributed lognormal with parameters $\mu(e)$ and $\sigma^{2} T$, where

$$
\mu(e)=\ln \left(P_{0}(e)\right)+\left(r_{f}-\frac{\sigma^{2}}{2}\right) T .
$$

Then $\log \left(P_{T}\right)=\mu(e)+u \sigma \sqrt{T}$ is normal with mean $\mu(e)$ and standard deviation $\sigma \sqrt{T}$. We denote the density of $P_{T}$ for a given level of effort $e$ by $f\left(P_{T} \mid e\right)$ :

$$
f\left(P_{T} \mid e\right)=\frac{1}{P_{T} \sqrt{2 \pi T} \sigma} \exp \left\{-\frac{\left[\ln P_{T}-\mu(e)\right]^{2}}{2 \sigma^{2} T}\right\} .
$$

Then the likelihood ratio is

$$
\frac{d f\left(P_{T} \mid e\right) / d e}{f\left(P_{T} \mid e\right)}=\mu^{\prime}(e) \frac{\ln P_{T}-\mu(e)}{\sigma^{2} T}
$$

with $\mu^{\prime}(e)=P_{0}^{\prime}(e) / P_{0}(e)$. This maps our model into Holmström's (1979) framework. Denote the Lagrange multipliers on the participation constraint (PC) and the incentive compatibility constraint (IC) by $\lambda_{P C}$ and $\lambda_{I C}$ respectively. Both Lagrange multipliers need to be positive. Then the optimal contract $\pi^{*}\left(P_{T}\right)$ for a given level of effort $e$ is fully described by Holmström's equation (7), adapted to our model:

$$
\begin{aligned}
\left(W_{0} \exp \left(r_{f} T\right)+\pi^{*}\left(P_{T}\right)\right)^{\gamma} & =\lambda_{P C}+\lambda_{I C} \mu^{\prime}(e) \frac{\ln P_{T}-\mu(e)}{\sigma^{2} T} \equiv \alpha_{0}+\alpha_{1} \ln P_{T} \\
\text { where }: \alpha_{1} & =\frac{\lambda_{I C}}{\sigma^{2} T} \frac{P_{0}^{\prime}(e)}{P_{0}(e)}>0, \alpha_{0}=\lambda_{P C}-\alpha_{1} \mu(e)
\end{aligned}
$$

Observe that the limited wealth constraint (10) implies that $W_{T} \geq 0$ for all $P_{T}$, so the argument of the utility function cannot be negative. Similarly, the principal enjoys limited liability and cannot pay a compensation larger than the value of the firm itself. Therefore, the constraints on $\pi\left(P_{T}\right)$ 
are: ${ }^{42}$

$$
-W_{0} \exp \left(r_{f} T\right) \leq \pi\left(P_{T}\right) \leq P_{T}
$$

However, the right hand side of (22) will be negative for $P_{T}<\exp \left(-\alpha_{0} / \alpha_{1}\right)$. We therefore obtain (18), once we require a minimum level of consumption $\varepsilon \geq 0$ for the CEO. Standard analysis of (18) yields the following results. The solution $\pi^{*}$ to the optimal contracting problem is constant at $-W_{0} \exp \left(r_{f} T\right)$ for all prices below $\bar{P}_{T}$. At $P_{T}=\bar{P}=\exp \left(\left(\varepsilon^{\gamma}-\alpha_{0}\right) / \alpha_{1}\right)$ the function is not differentiable and to the right of $P_{T}=\bar{P}$ its slope is positive. The function is convex at $P_{T}=\bar{P}$ : for any $P_{1}, P_{2}$ such that $P_{1}<\bar{P}<P_{2}$ and for any $a \in[0 ; 1]$ we have that $a \pi^{*}\left(P_{1}\right)+(1-a) \pi^{*}\left(P_{2}\right)>$ $\pi^{*}(\bar{P})$. The function is concave over the whole interval $[\bar{P}, \infty]$ if $\gamma \geq 1$. For $\gamma<1$, the $\pi^{*}$-function is convex if

$$
P_{T} \in\left[\bar{P}, \exp \left\{\frac{1-\gamma}{\gamma}-\frac{\alpha_{0}}{\alpha_{1}}\right\}\right]
$$

and concave to the right of this interval, with an inflection point that is decreasing in $\gamma$. The optimal contract $\pi^{*}\left(P_{T}\right)$ is therefore neither convex nor concave.

\section{A.2 Proof of Proposition 1:}

We prove the claim by contradiction. Suppose there would be an optimal effort level $e^{*}<\bar{e}$. This effort level would have to satisfy (15), so that $U P P S\left(\phi^{*}, n_{S}^{*}, n_{O}^{*} ; \gamma, P\left(e^{*}\right)\right)=k\left(e^{*}\right)$. Note that $k(e)$ is strictly increasing in $e$ :

$$
\frac{d k(e)}{d e}=\exp \left(-r_{f} T\right) \frac{C^{\prime \prime}(e) P^{\prime}(e)-C^{\prime}(e) P^{\prime \prime}(e)}{P^{\prime}(e)^{2}}>0
$$

as $C$ and $P$ are both increasing and $C$ is convex and $P$ is concave. However, then (15) can only be satisfied if

$$
U P P S\left(\phi^{*}, n_{S}^{*}, n_{O}^{*} ; \gamma, P\left(e^{*}\right)\right)<U P P S\left(\phi^{*}, n_{S}^{*}, n_{O}^{*} ; \gamma, P(\bar{e})\right)=U P P S\left(\phi^{d}, n_{S}^{d}, n_{O}^{d} ; \gamma, P_{0}\right)
$$

which is ruled out by (17). For $n_{O}^{*} \leq 0, E\left[U\left(W_{T}, e\right)\right]$ is a concave function of $P$, as $U$ is concave and $W_{T}$ is then linear in $P_{T}$. Then (17) is always satisfied.

\footnotetext{
${ }^{42}$ For a discussion on limits on the sharing function $\pi$ see also Holmström (1979), p. 77.
} 


\section{B Construction of the Dataset}

This appendix provides a more detailed discussion of the construction of our non-firm wealth variable $W_{0}$ and the representative option.

Wealth. Every CEO is assumed to have zero wealth on the date when she enters the database. Denote the end of the fiscal year when the CEO enters the database by $t_{E}$, so we assume that $W_{t_{E}-1}=0$. Similarly, denote the end of the fiscal year where we observe and evaluate the contract by $t_{0}$ ("today"). Then for each year we calculate the CEO's net cash inflow as follows:

\footnotetext{
Fixed salary (after tax)

+ Dividend income from shares held in own company (after tax)

$+\quad$ Value of restricted stock granted

- Personal taxes on restricted stock that vest during the year

+ Net value realized from exercising options (after tax)

- Cash paid for purchasing additional stock

$=$ Cash Income.
}

Here, fixed salary is defined as the sum of the following four ExecuComp data types: Salary, Bonus, Other Annual, All Other Total, and long-term incentive pay (LTIP). Following Hall and Liebman (2000), we use the following personal tax rates: $31 \%$ for $1992,39.6 \%$ for 1993 , and $42 \%$ from 1994 onwards.

As ExecuComp records only the value but not the number of restricted shares granted, we add the value to cash income and deduct the cash needed for purchasing the change in stockholdings. Likewise, we add the value realized from exercising options. So if the CEO exercises $n$ options but does not sell any shares and does not receive any restricted stock grants in this period, we add the net value realized from exercising the options (i.e. the value of the $n$ shares at the time the options were exercised minus the strike price) to cash income and deduct $n$ times the market price of the shares at fiscal year end. Due to fluctuations in stock prices, this method will lead to some errors. However, there is no alternative to this approach, because we do not know the strike price of the options exercised. If the CEO sells more shares than she receives from restricted grants or exercising options, her stock holdings decrease and the item "cash paid for purchasing additional stock" above becomes negative. If a CEO changed her employer during her history in the database, we assume 
that she sold all unrestricted stock in the old company and exercised all exercisable options for which we know the strike price before she has been hired by the new company. Restricted stock and unexercisable options are assumed to be lost. In addition, we assume that she bought the shares held in the new company that were not granted to her in the first year.

Denote the cash inflow during fiscal year $t$ by $y_{t}$. We assume that the CEO invests all her surplus cash at the risk-free rate of interest and does not consume. We assume that all cash inflows are realized at the end of the fiscal year and invested at the risk-free rate $r_{f}^{t+1}$ during the next fiscal year. Data on the annual one-year risk-free rate $r_{f}$ has been obtained from the Federal Reserve Board's website (http://www.federalreserve.gov). Then we obtain our estimate for the CEO's (non-stock) wealth:

$$
W_{0}=y_{t_{0}}+\sum_{t=t_{E}}^{t_{0}-1} y_{t} \prod_{s=t+1}^{t_{0}}\left(1+r_{f}^{s}\right)
$$

Stock Options. We approximate the options portfolios held by the CEOs at the end of the 1999 fiscal year using the algorithm proposed by Core and Guay (2002a). Then we construct a representative option that summarizes the salient features of this option portfolio. We do this by creating a composite option that matches the value and the option delta of the option portfolio. Denote the number of options of type $\tau$ (with strike price $K^{\tau}$ and maturity $T^{\tau}$ ) by $n_{O}^{\tau}$. We set the number of composite options held by the CEO to $n_{O}=\sum_{\tau} n_{O}^{\tau}$ and denote by $B S$ the Black-Scholes value of this option and by $N\left(d_{1}\right)$ the option delta. Then we determine the maturity $T$ and the strike price $K$ of the composite option by solving the following system of equations for each CEO:

$$
\begin{gathered}
\sum_{\tau} n_{O}^{\tau} B S\left(P_{0}, K^{\tau}, \sigma, r_{f}, 0.7 T^{\tau}\right)=n_{O} B S\left(P_{0}, K, \sigma, r_{f}, T\right) \\
\sum_{\tau} n_{O}^{\tau} N\left(d_{1}^{\tau}\right)=n_{O} N\left(d_{1}\right)
\end{gathered}
$$

Conditions (24) and (25) form a system of two equations in the two unknowns $K, T$, which represent the free parameters of the composite option. We take into account the fact that most CEOs exercise their stock options before maturity by multiplying $T^{\tau}$ by 0.7 before calculating the representative option (see Huddart and Lang, 1996, and Carpenter, 1998). For $r_{f}$ we use the U.S. government bond yield with 6-year maturity from January 2000, because the average maturity of the representative options is 5.9 years in our sample as shown in Table 1 . The two remaining parameters $\left(P_{0}, \sigma\right)$ are given by the data. Hence, our procedure establishes parameters 
for the options that do not change the value of these options to shareholders and how this valuation

changes as a function of the stock price. For CEOs who do not have any options, we set $K=P_{0}$ and $T=10$ as these are the typical values for newly granted options. 


\section{References}

[1] Abowd, John M., and David S. Kaplan, 1999, Executive Compensation: Six Questions That Need Answering, Journal of Economic Perspectives 13, no. 4 (Fall), pp. 145-169

[2] Ait-Sahalia, Yacine, and Andrew W. Lo, 2000, Non-Parametric Risk Management and Implied Risk Aversion, Journal of Econometrics 94, pp. 9-51

[3] Aggarwal, Rajesh K., and Andrew Samwick, 1999, The Other Side of the Trade-Off: The Impact of Risk on Executive Compensation, Journal of Political Economy 107, no. 1 (February), pp. 65-105

[4] Baker, George P., and Brian J. Hall, 2004, CEO Incentives and Firm Size, Journal of Labor Economics 22 , no. 4 , pp. $767-798$

[5] Bebchuk, Lucian Arye, and Jesse M. Fried, 2003, Executive Compensation As an Agency Problem, Journal of Economic Perspectives 17, pp. 71-92

[6] — 2004, Pay Without Performance - The Unfulfilled Promise of Executive Compensation, Cambridge (MA) and London (Harvard University Press)

[7] Becker, Bo, 2005, Wealth, Risk Aversion and CEO Compensation, Journal of Finance, forthcoming

[8] Bertrand, Marianne, and Sendhil Mullainathan, 2000, Agents With and Without Principals, American Economic Review 90, no. 2 (May), pp. 203-208

[9] Brickley, James A., 2003, Empirical Research on CEO Turnover and Firm-Performance: a Discussion, Journal of Accounting and Economics 36, no. 1-3 (December), pp. 227-233

[10] Cai, Jie, and Anand M. Vijh, 2005, Executive Stock and Option Valuation in a Two State-Variable Framework: Allowing Optimal Investment of Outside Wealth in the Riskfree Asset and the Market Portfolio, Journal of Derivatives 12, pp. 9-27

[11] Campbell, John Y.; Andrew W. Lo, and A. Graig MacKinlay, 1997, The Econometrics of Financial Markets, Princeton,. N.J. (Princeton University Press)

[12] Carpenter, Jennifer N., 1998, The Exercise and Valuation of Executive Stock Options, Journal of Financial Economics 48, no. 2, pp. 127-158

[13] - 2000, Does Option Compensation Increase Managerial Risk Appetite?, Journal of Finance 55, no. 5 (October), pp. 2311-2331

[14] Chetty, Raj, 2003, A New Method of Estimating Risk Aversion, NBER Working Paper, (September)

[15] Core, John E., and Wayne R. Guay, 2002a, Estimating the Value of Stock Option Portfolios and Their Sensitivities to Price and Volatility, Journal of Accounting Research 40, no. 3 (June), pp. 613-640

[16] - 2002b, The Other Side of the Trade-Off: The Impact of Risk on Executive Compensation - A Revised Comment, Mimeo, University of Pennsylvania, (November)

[17] Core, John E.; Wayne R. Guay, and David F. Larcker, 2002, Executive Equity Compensation and Incentives: A Survey, Economic Policy Review 9, no. 8 , pp. 27-50

[18] Core, John E.; Wayne R. Guay, and Randall S. Thomas, 2004, Is U.S. CEO Compensation Inefficient Pay Without Performance?, Mimeo, University of Pennsylvania, (December)

[19] Core, John E.; Wayne R. Guay, and Robert E. Verrecchia, 2003, Price Versus Non-Price Performance Measures in Optimal CEO Compensation Contracts, Mimeo, University of Pennsylvania, (May)

[20] Core, John E.; Holthausen Robert W., and David F. Larcker, 1999, Corporate Governance, Chief Executive Officer Compensation, and Firm Performance, Journal of Financial Economics 51, no. 3 , pp. 371-406 
[21] Coughlan, A. T., and R. M. Schmidt, 1985, Executive Compensation, Management Turnover, and Firm Performance: an Empirical Investigation, Journal of Accounting and Economics 17, pp. 331-358

[22] Dechow, Patricia M.; Amy P. Hutton, and Richard G. Sloan, 1996, Economic Consequences of Accounting for Stock-Based Compensation, Journal of Accounting Research 34, (Supplement), pp. 1-20

[23] Dybvig, P., and J. Zender, 1991, Capital Structure and Dividend Irrelevance With Asymmetric Information, Review of Financial Studies 4, pp. 201-219

[24] Farmer, Roger E. A., and Ralph A. Winter, 1986, The Role of Options in the Resolution of AgencyProblems: A Comment, Journal of Finance 41, no. 5 (December), pp. 1157-1170

[25] Feltham, Gerald A., and Martin G. H. Wu, 2001, Incentive Efficiency of Stock Versus Options, Review of Accounting Studies 6, no. 1 (March), pp. 7-28

[26] Garen, John E., 1994, Executive Compensation and Principal-Agent Theory, Journal of Political Economy 102, no. 6 (December), pp. 1175-1199

[27] Garvey, Gerald T., and Todd T. Milbourn, 2002, Do Stock Prices Incorporate the Potential Dilution of Employee Stock Options?, Mimeo, Claremont University, (November)

[28] Grossman, Sanford J., and Oliver D. Hart, 1983, An Analysis of the Principal-Agent Problem, Econometrica 51, no. 1 (January), pp. 7-45

[29] Guay, Wayne R., 1999, The Sensitivity of CEO Wealth to Equity Risk: An Analysis of the Magnitude and Determinants, Journal of Financial Economics 53, no. 1 (July), pp. 43-71

[30] Guay, Wayne R.; S. P. Kothari, and Richard G. Sloan, 2003, Accounting for Employee Stock Options, American Economic Review 93, pp. 405-409

[31] Hall, Brian J., and Thomas A. Knox, 2004, Underwater Options and the Dynamics of Executive Payto-Performance Sensitivities, Journal of Accounting Research 42, no. 2 (May), pp. 365-412

[32] Hall, Brian J., and Jeffrey B. Liebman, 1998, Are CEOs Really Paid Like Bureaucrats?, Quarterly Journal of Economics 112, no. 3 (August), pp. 653-691

[33] — 2000, The Taxation of Executive Compensation, NBER Working Paper, no. 7596 (March)

[34] Hall, Brian J., and Kevin J. Murphy, 2000, Optimal Exercise Prices for Executive Stock Options, American Economic Review 90, (May), pp. 209-214

[35] - 2002, Stock Options for Undiversified Executives, Journal of Accounting and Economics 33, no. 2 (April), pp. 3-42

[36] — 2003, The Trouble With Stock Options, Journal of Economic Perspectives 17, pp. 49-70

[37] Hanlon, Michelle; Shivaram Rajgopal, and Terry Shevlin, 2003, Are Executive Stock Options Associated With Future Earnings, Journal of Accounting and Economics 36, (December), pp. 3-43

[38] Haubrich, Joseph G., 1994, Risk Aversion, Performance Pay, and the Principal-Agent-Problem, Journal of Political Economy 102, no. 2 (April), pp. 258-275

[39] Haubrich, Joseph G., and Ivilina Popova, 1998, Executive Compensation: A Calibration Approach, Economic Theory 12, (December), pp. 561-581

[40] Hemmer, Thomas; Oliver Kim, and Robert E. Verrecchia, 2000, Introducing Convexity into Optimal Compensation Contracts, Journal of Accounting and Economics 28, pp. 307-327

[41] Hemmer, Thomas; Steve Matsunaga, and T. Shevlin, 1998, Optimal Exercise and the Cost of Granting Employee Stock Options With a Reload Provision, Journal of Accounting Research 36, no. 2, pp. $231-55$ 
[42] Henderson, Vicky, 2002, Stock Based Compensation: Firm-Specific Risk, Efficiency, and Incentives, Oxford Financial Research Centre Preprint, no. 2002-FE-01

[43] Himmelberg, Charles P., and Ronald Glenn Hubbard, 2000, Incentive Pay and the Market for CEOs: An Analysis of Pay-for-Performance Sensitivity, Mimeo, Columbia University, (October)

[44] Himmelberg, Charles P.; Ronald Glenn Hubbard, and Darius Palia, 1999, Understanding the Determinants of Managerial Ownership and the Link Between Ownership and Performance, Journal of Financial Economics 53, pp. 353-384

[45] Holmström, Bengt, 1979, Moral Hazard and Observability, Bell Journal of Economics 10, pp. 74-91

[46] Holmström, Bengt, and J. Ricarti Costa, 1986, Managerial Incentives and Capital Management, Quarterly Journal of Economics 101, no. 4 (November), pp. 835-860

[47] Huddart, Steven J., 1994 , Employee Stock Options, Journal of Accounting and Economics 18, pp. 207-231

[48] Huddart, Steven J.; Ravi Jagannathan, and P. Jane Saly, 1999, Valuing the Reload Features of Executive Stock Options, NBER Working Paper, no. 7020 (March)

[49] Huddart, Steven J., and Mark Lang, 1996, Employee Stock Option Exercises - An Empirical Analysis, Journal of Accounting and Economics 21, pp. 5-43

[50] Inderst, Roman, and Holger M. Müller, 2003, A Theory of Broad-Based Option Pay, Mimeo, London School of Economics, (November)

[51] Ingersoll, Jonathan E. Jr., 2002, The Subjective and Objective Evaluation of Incentive Stock Options, Yale ICF Working Paper, no. 02-07 (February)

[52] Jensen, Michael C., and Kevin J. Murphy, 1990, Performance Pay and Top-Management Incentives, Journal of Political Economy 98, no. 2 (April), pp. 225-264

[53] Jenter, Dirk C., 2002, Executive Compensation, Incentives, and Risk, MIT Sloan School Working Paper, (April)

[54] Jewitt, Ian, 1988, Justifying the First-Order Approach to Principal-Agent Problems, Econometrica 56, no. 5 (September), pp. 1177-1190

[55] Johnson, Shane A., and Yisong S. Tian, 2000a, Indexed Executive Stock Options, Journal of Financial Economics 57, no. 1 (July), pp. 35-64

[56] 2000b, The Value and Incentive Effects of Nontraditional Executive Stock Option Plans, Journal of Financial Economics 57, no. 1 (July), pp. 3-34

[57] Jost, Peter J., and Florian C. Wolff, 2003, Subjective Expected Utility Theory and the Value and Incentive Effects of Stock Options for Executives, WHU Department of Organization Theory Working Paper, no. 03-05 (May)

[58] Kaplan, Steven N, 1994, Top Executive Rewards and Firm Performance: A Comparison of Japan and the United States, Journal of Political Economy 102, no. 3 , pp. 510-545

[59] Kedia, Simi, and Abon Mozumdar, 2002, Performance Impact of Employee Stock Options, Mimeo, Harvard University, (January)

[60] Lambert, Richard A., and David F. Larcker, 2004, Stock Options, Restricted Stock, and Incentives, Mimeo, University of Pennsylvania, (April)

[61] Lambert, Richard A.; David F. Larcker, and Robert Verrecchia, 1991, Portfolio Considerations in Valuing Executive Compensation, Journal of Accounting Research 29, no. 1 (Spring), pp. 129-149 
[62] Li, Ying, 2002, Maintaining Optimal CEO Incentives Through Equity Grants and CEO Portfolio Rebalancing, MIT Sloan Working Paper, no. 4371-02 (August)

[63] Margiotta, M.-M., and R. M. Miller, 2000, Managerial Compensation and the Cost of Moral Hazard, International Economic Review 41, no. 3 (August), pp. 669-719

[64] Meulbroek, Lisa K., 2001, The Efficiency of Equity-Linked Compensation: Understanding the Full Cost of Awarding Executive Stock Options, Financial Management 30, no. 2 (Summer), pp. 5-30

[65] Murphy, Kevin J., 1999, Executive Compensation, in: Ashenfelter, O., and D. Cards (editors): Handbook of Labor Economics, 3, Amsterdam, pp. 2485-563

[66] Nohel, Tom, and Steven Todd, 2005, Executive Compensation, Managerial Risk Aversion, and the Choice of Risky Projects, Journal of Corporate Finance 11, no. 1-2 (March), pp. 229-251

[67] Oyer, Paul, 2004, Why Do Firms Use Incentives That Have No Incentive Effects?, Journal of Finance 59, no. 4 (August), pp. 1619-1650

[68] Oyer, Paul, and Scott Schaefer, 2003, A Comparison of Options, Restricted Stock, and Cash for Employee Compensation, Mimeo, Stanford University, (September)

[69] — 2005, Why Do Some Firms Give Stock Options to All Employees? An Empirical Examination of Alternative Theories, Journal of Financial Economics 76, no. 1 (April), pp. 99-132

[70] Prendergast, Canice, 1999, The Provision of Incentives in Firms, Journal of Economic Literature 37, (March), pp. 7-63

[71] Rajgopal, Shivaram, and Terry J. Shevlin, 2002, Empirical Evidence on the Relation Between Stock Option Compensation and Risk Taking, Journal of Accounting and Economics 33, no. 2 , pp. 145-171

[72] Ross, Stephen A., 1976, Options and Efficiency, Quarterly Journal of Economics 90, no. 1 (February), pp. $75-90$

[73] - 2004, Compensation, Incentives, and the Duality of Risk Aversion and Riskiness, Journal of Finance 59, no. 1 (February), pp. 207-225

[74] Sircar, Ronnie, and Wei Xiong, 2003, Evaluating Option Incentives, Mimeo, Princeton University, (May)

[75] Smith, Clifford, and Rene Stulz, 1985, The Determinants of Firm's Hedging Policies, Journal of Financial and Quantitative Analysis 20, pp. 391-405

[76] Tian, Yisong S., 2001, Optimal Contracting, Incentive Effects and the Valuation of Executive Stock Options, Mimeo, York University (Canada), (April)

[77] Towers Perrin, 2004, Stock Options Around the World, no. TP197-01

[78] Tufano, Peter, 1996, Who Manages Risk? An Examination of Risk Management Practices in the Gold Mining Industry, Journal of Finance 51, no. 4 (September), pp. 1097-1137

[79] Williams, Melissa A., and Ramesh P. Rao, 2000, CEO Stock Options and Equity Risk Incentives, Mimeo, Georgia State University, (July)

[80] Yermack, David, 1995, Do Corporations Award CEO Stock Options Effectively?, Journal of Financial Economics 39, pp. 237-269 


\section{Table 1: Description of the dataset}

This table displays mean, median, standard deviation, minimum and maximum of twelve variables. Panel A describes our sample of 598 US CEOs. Panel B describes all 1,417 executives who were CEO in 2000 according to the ExecuComp database. Panel B also contains the statistic of the two-sample t-test for equal mean (allowing for different variances). Before calculating this statistic, we removed all observations from the sample in Panel B that are also contained in the sample in Panel A.

Panel A: Dataset with 598 U.S. CEOs

\begin{tabular}{llrrrrr}
\hline \multicolumn{1}{c}{ Variable } & \multicolumn{1}{c}{ Symbol } & Mean & Median & Std. Dev. & Minimum & Maximum \\
\hline Base Salary (\$ '000) & $\phi$ & 2,037 & 1,261 & 2,570 & 97 & 22,109 \\
Stock (\%) & $n_{S}$ & $2.29 \%$ & $0.29 \%$ & $6.00 \%$ & $0.00 \%$ & $46.34 \%$ \\
Options (\%) & $n_{O}$ & $1.29 \%$ & $0.84 \%$ & $1.82 \%$ & $0.00 \%$ & $24.32 \%$ \\
Options adjusted (\%) & $n_{O} \cdot \exp \{-d T\}$ & $1.22 \%$ & $0.76 \%$ & $1.79 \%$ & $0.00 \%$ & $24.32 \%$ \\
Value of stock (\$ mil) & $n_{S} \cdot P_{0}$ & 91.98 & 6.62 & 571.95 & 0.00 & $11,814.08$ \\
Value of options (\$ mil) & $n_{O} \cdot B S$ & 29.47 & 6.11 & 104.42 & 0.00 & $1,334.43$ \\
Market Value (\$ mil) & $P_{0}$ & 9,857 & 1,668 & 27,845 & 7 & 280,114 \\
Wealth (\$ mil) & $W_{0}$ & 34.60 & 6.86 & 234.79 & 0.03 & $5,431.72$ \\
Option Delta & $\mathrm{N}\left(d_{1}\right)$ & 0.834 & 0.856 & 0.126 & 0.001 & 1.000 \\
Maturity (years) & $T$ & 5.89 & 5.54 & 1.96 & 1.20 & 22.18 \\
Volatility & $\sigma$ & 0.377 & 0.335 & 0.196 & 0.136 & 3.487 \\
Age of CEO & & 57 & 57 & 7 & 36 & 84 \\
\hline
\end{tabular}

Panel B: All 1,417 ExecuComp CEOs in 2000

\begin{tabular}{lcrrrrrr}
\hline \multicolumn{1}{c}{ Variable } & Symbol & Mean & Median & Std. Dev. & Minimum & Maximum & $\begin{array}{c}\text { T-test } \\
\text { statistic }\end{array}$ \\
\hline Base Salary (\$ '000) & $\phi$ & 1,718 & 1,059 & 3,150 & 0 & 90,000 & 3.43 \\
Stock (\%) & $n_{S}$ & $2.97 \%$ & $0.35 \%$ & $6.78 \%$ & $0.00 \%$ & $56.42 \%$ & -3.32 \\
Options (\%) & $n_{O}$ & $1.45 \%$ & $0.96 \%$ & $1.88 \%$ & $0.00 \%$ & $27.93 \%$ & -2.74 \\
Value of stock (\$ mil) & $n_{S} \cdot P_{0}$ & 132.44 & 6.45 & $1,385.87$ & 0.00 & $47,838.75$ & -1.07 \\
Market Value (\$ mil.) & $P_{0}$ & 8,012 & 1,256 & 27,551 & 7 & 508,329 & 2.15 \\
Stock Price Volatility & $\sigma$ & 0.435 & 0.384 & 0.205 & 0.136 & 3.487 & -9.36 \\
Age of CEO & & 55 & 55 & 8 & 29 & 86 & 7.41 \\
\hline
\end{tabular}




\section{Table 2: Optimal contracts with non-negative option holdings}

This table describes the optimal restricted option contract, i.e. the optimal contract subject to the constraint that option holdings must be non-negative $\left(n_{O} \geq 0\right)$. Panel A displays mean and median of the three contract parameters: base salary $\phi^{*}$, stock holdings $n_{S}{ }^{*}$ and adjusted option holdings $n_{O}{ }^{*} \exp \{-d T\}$. In addition, it shows the fraction of CEOs with positive option holdings $\left(n_{O^{*}}>0\right)$ and the fraction of CEOs with negative base salaries $\left(\phi^{*}<0\right)$. Panel B describes the additional investment the CEO should make into her own company according to the optimal contract, and the savings the firm could realize by switching from observed contracts to optimal contracts. Wealth that must be invested is equal to $-\min \left(\phi^{*}, 0\right)$. Investment relative to wealth is this investment scaled by the CEO's wealth, $-\min \left(\phi^{*}, 0\right) / W_{0}$. Savings are the difference in compensation costs between observed contracts and optimal contracts, $\pi_{0}{ }^{d}-\pi_{0}{ }^{*}$. Savings in percent of total pay are $\left(\pi_{0}{ }^{d}-\pi_{0}{ }^{*}\right) / \pi_{0}{ }^{d}$, and savings in percent of firm value are $\left(\pi_{0}{ }^{d}-\pi_{0}{ }^{*}\right) / P_{0}$. Results are shown for nine different values of the parameter of risk aversion $\gamma$. For $\gamma=0.5$, the table contains 3 CEOs for which we could not verify condition (17). This condition ensures that the first-order approach is always valid. For all remaining $\gamma-\mathrm{CEO}$ combinations condition (17) could be verified.

\section{Panel A: Parameters of optimal contracts}

\begin{tabular}{|c|c|c|c|c|c|c|c|c|c|}
\hline \multirow{2}{*}{$\begin{array}{c}\text { Risk } \\
\text { aversion }\end{array}$} & \multirow{2}{*}{$\begin{array}{l}\text { Number } \\
\text { of CEOs }\end{array}$} & \multicolumn{2}{|c|}{$\begin{array}{c}\text { Base salary } \\
(\mathbf{\$} \mathbf{0 0 0})\end{array}$} & \multicolumn{2}{|c|}{ Stock holdings } & \multicolumn{2}{|c|}{ Option holdings } & \multirow{2}{*}{$\begin{array}{c}\text { Fraction } \\
\text { with } \\
\text { options }>0\end{array}$} & \multirow{2}{*}{$\begin{array}{c}\text { Fraction } \\
\text { with base } \\
\text { salary }<0\end{array}$} \\
\hline & & Mean & Median & Mean & Median & Mean & Median & & \\
\hline 0.5 & 596 & $-5,593$ & $-1,959$ & $3.186 \%$ & $1.035 \%$ & $0.065 \%$ & $0.000 \%$ & $17.45 \%$ & $78.69 \%$ \\
\hline 1 & 597 & $-4,659$ & $-1,406$ & $3.089 \%$ & $0.987 \%$ & $0.038 \%$ & $0.000 \%$ & $11.39 \%$ & $72.53 \%$ \\
\hline 2 & 598 & $-2,997$ & -380 & $2.897 \%$ & $0.829 \%$ & $0.012 \%$ & $0.000 \%$ & $5.18 \%$ & $61.04 \%$ \\
\hline 3 & 598 & $-1,652$ & 92 & $2.746 \%$ & $0.724 \%$ & $0.003 \%$ & $0.000 \%$ & $1.34 \%$ & $46.99 \%$ \\
\hline 4 & 598 & -651 & 321 & $2.639 \%$ & $0.640 \%$ & $0.000 \%$ & $0.000 \%$ & $0.33 \%$ & $35.28 \%$ \\
\hline 5 & 598 & 44 & 491 & $2.563 \%$ & $0.570 \%$ & $0.000 \%$ & $0.000 \%$ & $0.00 \%$ & $25.42 \%$ \\
\hline 6 & 598 & 519 & 625 & $2.508 \%$ & $0.513 \%$ & $0.000 \%$ & $0.000 \%$ & $0.00 \%$ & $18.39 \%$ \\
\hline 8 & 598 & 1,091 & 803 & $2.438 \%$ & $0.441 \%$ & $0.000 \%$ & $0.000 \%$ & $0.00 \%$ & $10.03 \%$ \\
\hline 10 & 598 & 1,402 & 941 & $2.396 \%$ & $0.414 \%$ & $0.000 \%$ & $0.000 \%$ & $0.00 \%$ & $5.52 \%$ \\
\hline
\end{tabular}

Panel B: CEO investment and firm savings

\begin{tabular}{|c|c|c|c|c|c|c|c|c|}
\hline \multirow{2}{*}{$\begin{array}{c}\text { Risk } \\
\text { aversion }\end{array}$} & \multicolumn{2}{|c|}{$\begin{array}{l}\text { Wealth that must be } \\
\text { invested (mean) }\end{array}$} & \multicolumn{2}{|c|}{ Savings (\$ '000) } & \multicolumn{2}{|c|}{$\begin{array}{c}\text { Savings in percent } \\
\text { of total pay }\end{array}$} & \multicolumn{2}{|c|}{$\begin{array}{c}\text { Savings in percent } \\
\text { of firm value }\end{array}$} \\
\hline & in \$'000 & $\%$ of wealth & Mean & Median & Mean & Median & Mean & Median \\
\hline 0.5 & 5,830 & $38.50 \%$ & 673 & 197 & $1.73 \%$ & $1.02 \%$ & $0.04 \%$ & $0.01 \%$ \\
\hline 1 & 4,956 & $31.43 \%$ & 2,229 & 567 & $4.93 \%$ & $3.25 \%$ & $0.10 \%$ & $0.03 \%$ \\
\hline 2 & 3,435 & $18.74 \%$ & 7,156 & 1,513 & $12.77 \%$ & $9.42 \%$ & $0.23 \%$ & $0.08 \%$ \\
\hline 3 & 2,258 & $10.51 \%$ & 12,278 & 2,449 & $19.58 \%$ & $15.58 \%$ & $0.34 \%$ & $0.14 \%$ \\
\hline 4 & 1,432 & $5.42 \%$ & 16,156 & 3,297 & $24.54 \%$ & $20.50 \%$ & $0.42 \%$ & $0.19 \%$ \\
\hline 5 & 926 & $2.92 \%$ & 19,013 & 3,884 & $28.11 \%$ & $24.74 \%$ & $0.47 \%$ & $0.22 \%$ \\
\hline 6 & 614 & $1.63 \%$ & 21,121 & 4,395 & $30.76 \%$ & $28.32 \%$ & $0.52 \%$ & $0.25 \%$ \\
\hline 8 & 287 & $0.59 \%$ & 23,850 & 4,925 & $34.30 \%$ & $32.76 \%$ & $0.57 \%$ & $0.29 \%$ \\
\hline 10 & 155 & $0.26 \%$ & 25,493 & 5,234 & $36.49 \%$ & $35.46 \%$ & $0.60 \%$ & $0.31 \%$ \\
\hline
\end{tabular}




\section{Table 3: Optimal contracts with unrestricted option holdings}

This table describes the optimal unrestricted option contract, i.e. the optimal contract under the weaker restriction that the CEO cannot sell more options than the number of shares she owns $\left(n_{S}+n_{O} \exp \{-d T\} \geq\right.$ 0 ). Panel A displays mean and median of the three contract parameters: base salary $\phi^{*}$, stock holdings $n_{S}{ }^{*}$ (which is the Pay for Performance Sensitivity for $P_{T}<K$ ), and the sum of stock holdings and adjusted option holdings $n_{S}{ }^{*}+n_{O}{ }^{*} \exp \{-d T\}$ (which is the Pay for Performance Sensitivity for $P_{T}>K$ ). In addition, the table shows the fraction of CEOs with Pay for Performance Sensitivity equal to zero for $P_{T}>K\left(n_{S}{ }^{*}+\right.$ $\left.n_{O}{ }^{*} \exp \{-d T\}=0\right)$ and the fraction of CEOs with negative base salary $\left(\phi^{*}<0\right)$. Panel B describes the additional investment the CEO should make into her own company according to the optimal contract, and the savings the firm could realize by switching from observed contracts to optimal contracts. Wealth that must be invested is equal to $-\min \left(\phi^{*}, 0\right)$. Investment relative to wealth is this investment scaled by the CEO's wealth, $-\min \left(\phi^{*}, 0\right) / W_{0}$. Savings are the difference in compensation costs between observed contracts and optimal contracts, $\pi_{0}{ }^{d}-\pi_{0}{ }^{*}$. Savings in percent of total pay are $\left(\pi_{0}{ }^{d}-\pi_{0}{ }^{*}\right) / \pi_{0}{ }^{d}$, and savings in percent of firm value are $\left(\pi_{0}{ }^{d}-\pi_{0}{ }^{*}\right) / P_{0}$. Results are shown for nine different values of the parameter of risk aversion $\gamma$. For $\gamma=0.5$, the table contains 3 CEOs for which we could not verify condition (17). This condition ensures that the first-order approach is always valid. For all remaining $\gamma$-CEO combinations condition (17) could be verified.

\section{Panel A: Parameters of optimal contracts}

\begin{tabular}{|c|c|c|c|c|c|c|c|c|c|}
\hline \multirow[t]{2}{*}{$\begin{array}{c}\text { Risk } \\
\text { aversion }\end{array}$} & \multirow[t]{2}{*}{$\begin{array}{l}\text { Number } \\
\text { of CEOs }\end{array}$} & \multicolumn{2}{|c|}{$\begin{array}{c}\text { Base salary } \\
\left(\${ }^{\prime} 000\right)\end{array}$} & \multicolumn{2}{|c|}{$\begin{array}{l}\text { Stock holdings } \\
\left(\text { PPS for } P_{T}<K\right)\end{array}$} & \multicolumn{2}{|c|}{$\begin{array}{r}\text { Options + stock } \\
\left(\text { PPS for } P_{T}>K\right)\end{array}$} & $\begin{array}{c}\text { Fraction } \\
\text { with PPS }=0\end{array}$ & \multirow{2}{*}{$\begin{array}{c}\text { Fraction } \\
\text { with base } \\
\text { salary }<0\end{array}$} \\
\hline & & Mean & Median & Mean & Median & Mean & Median & for $P_{T}>K$ & \\
\hline 0.5 & & $-28,871$ & $-5,638$ & $6.523 \%$ & $1.759 \%$ & $2.414 \%$ & $0.757 \%$ & $0.17 \%$ & $96.48 \%$ \\
\hline 1 & & $-28,157$ & -5 & $591 \%$ & 1.84 & $1.817 \%$ & $503 \%$ & & \\
\hline 2 & & -22 & & & & & & & \\
\hline 3 & & & & & & & & & \\
\hline 4 & & $-12,056$ & $-1,7$ & & & $20 \%$ & $18 \%$ & & \\
\hline 5 & & $-8,872$ & -773 & $4.148 \%$ & $1.011 \%$ & $0.136 \%$ & $0.009 \%$ & $82 \%$ & $67.23 \%$ \\
\hline 6 & & $-6,497$ & -278 & $3.794 \%$ & $0.884 \%$ & $0.078 \%$ & $0.004 \%$ & $80 \%$ & $18 \%$ \\
\hline 8 & & $-3,452$ & & 3.4 & 0.7 & 0.0 & $0.002 \%$ & $2 \%$ & \\
\hline 10 & 560 & $-1,663$ & 413 & $3.138 \%$ & $0.614 \%$ & $0.008 \%$ & $0.000 \%$ & $56.96 \%$ & $32.14 \%$ \\
\hline
\end{tabular}

Panel B: CEO investment and firm savings

\begin{tabular}{|c|c|c|c|c|c|c|c|c|}
\hline \multirow{2}{*}{$\begin{array}{c}\text { Risk } \\
\text { aversion }\end{array}$} & \multicolumn{2}{|c|}{$\begin{array}{l}\text { Wealth that must be } \\
\text { invested (mean) }\end{array}$} & \multicolumn{2}{|c|}{ Savings (\$ '000) } & \multicolumn{2}{|c|}{$\begin{array}{c}\text { Savings in percent } \\
\text { of total pay }\end{array}$} & \multicolumn{2}{|c|}{$\begin{array}{c}\text { Savings in percent } \\
\text { of firm value }\end{array}$} \\
\hline & in \$'000 & $\%$ of wealth & Mean & Median & Mean & Median & Mean & Median \\
\hline 0.5 & 28,909 & $81.97 \%$ & 3,640 & 339 & $3.54 \%$ & $1.78 \%$ & $0.13 \%$ & $0.02 \%$ \\
\hline 1 & 28,204 & $78.37 \%$ & 14,053 & 1,183 & $10.38 \%$ & $6.07 \%$ & $0.36 \%$ & $0.06 \%$ \\
\hline 2 & 23,073 & $64.28 \%$ & 38,481 & 3,852 & $25.57 \%$ & $20.59 \%$ & $0.86 \%$ & $0.22 \%$ \\
\hline 3 & 16,735 & $47.48 \%$ & 54,324 & 6,221 & $36.54 \%$ & $32.42 \%$ & $1.17 \%$ & $0.33 \%$ \\
\hline 4 & 12,315 & $33.68 \%$ & 65,4 & 7,731 & $43.71 \%$ & $42.31 \%$ & $1.38 \%$ & $0.41 \%$ \\
\hline 5 & 9,232 & $23.30 \%$ & 73,309 & 8,319 & $48.14 \%$ & $47.58 \%$ & $1.52 \%$ & $0.46 \%$ \\
\hline 6 & 6,979 & $16.24 \%$ & 78,468 & 9,481 & $51.45 \%$ & $51.97 \%$ & $1.63 \%$ & $0.49 \%$ \\
\hline 8 & 4,157 & $8.12 \%$ & 85,431 & 10,339 & $55.73 \%$ & $56.48 \%$ & $1.80 \%$ & $0.55 \%$ \\
\hline 10 & 2,569 & $4.29 \%$ & 82,490 & 10,172 & $57.91 \%$ & $59.21 \%$ & $1.89 \%$ & $0.59 \%$ \\
\hline
\end{tabular}




\section{Table 4: Optimal general nonlinear contract}

This table describes the optimal contract with the general nonlinear pay function $\pi\left(P_{T}\right)=$ $\min \left\{\left(\alpha_{0}+\alpha_{1} \ln P_{T}\right)^{1 / \gamma}, \varepsilon\right\}-W_{0} \exp \left(r_{f} T\right)$ from equation (18). We do not tabulate summary statistics for the parameters $\alpha_{0}, \alpha_{1}$, and $\varepsilon$, because they cannot be interpreted independently of each other. Instead, the table displays the median cut-off point $\bar{P} / P_{0}$ (where $\bar{P}$ is the point where the minimum $\varepsilon$ is attained) and the median change in wealth when the stock price changes from $P_{T}(0)$ to $P_{T}(u)$ where $u=-4,-1,+1,+4$. In addition, the table shows average savings as percentage of total pay $\left(\pi_{0}{ }^{d}-\pi_{0}{ }^{*}\right) / \pi_{0}{ }^{d}$ from switching from observed contracts to optimal contracts. Results are shown for nine different values of the parameter of risk aversion $\gamma$. For all $\gamma$-CEO combinations the general validity of the first-order approach (condition (17)) could be verified. The last row shows the corresponding statistics for the observed contracts. Results for $\gamma=$ 1 are not comparable to the results for other values of $\gamma$, because the utility function is not continuous in $\gamma$ at $\gamma=1$.

\begin{tabular}{|c|c|c|c|c|c|c|c|}
\hline \multirow{3}{*}{$\begin{array}{c}\text { Risk } \\
\text { aversion }\end{array}$} & \multirow{3}{*}{$\begin{array}{l}\text { Number } \\
\text { of CEOs }\end{array}$} & \multirow{3}{*}{$\begin{array}{c}\text { Median } \\
\bar{P} / P_{0}\end{array}$} & \multicolumn{4}{|c|}{ Median change in wealth if random variable $u$... } & \multirow{3}{*}{$\begin{array}{c}\text { Mean } \\
\text { savings as } \\
\text { percentage of } \\
\text { total pay }\end{array}$} \\
\hline & & & \multicolumn{2}{|c|}{... increases by ... } & \multicolumn{2}{|c|}{... decreases by ... } & \\
\hline & & & by 1 std & by 4 std & by 1 std & by 4 std & \\
\hline 0.5 & 595 & $7.12 \%$ & $70.03 \%$ & $391.02 \%$ & $-51.55 \%$ & $-99.89 \%$ & $4.79 \%$ \\
\hline 1 & 542 & $12.08 \%$ & $38.34 \%$ & $153.37 \%$ & $-38.34 \%$ & $-99.94 \%$ & $14.31 \%$ \\
\hline 2 & 596 & $4.21 \%$ & $11.99 \%$ & $42.00 \%$ & $-13.63 \%$ & $-99.58 \%$ & $33.90 \%$ \\
\hline 3 & 596 & $1.34 \%$ & $5.92 \%$ & $20.58 \%$ & $-6.72 \%$ & $-37.27 \%$ & $45.19 \%$ \\
\hline 4 & 596 & $0.53 \%$ & $3.67 \%$ & $12.81 \%$ & $-4.12 \%$ & $-21.47 \%$ & $51.82 \%$ \\
\hline 5 & 593 & $0.26 \%$ & $2.56 \%$ & $9.01 \%$ & $-2.85 \%$ & $-14.35 \%$ & $56.19 \%$ \\
\hline 6 & 587 & $0.13 \%$ & $1.92 \%$ & $6.78 \%$ & $-2.12 \%$ & $-10.40 \%$ & $59.07 \%$ \\
\hline 8 & 508 & $0.04 \%$ & $1.23 \%$ & $4.39 \%$ & $-1.34 \%$ & $-6.38 \%$ & $63.27 \%$ \\
\hline 10 & 286 & $0.04 \%$ & $0.90 \%$ & $3.23 \%$ & $-0.98 \%$ & $-4.58 \%$ & $65.41 \%$ \\
\hline $\begin{array}{l}\text { Observed } \\
\text { Contract }\end{array}$ & 598 & N/A & $107.40 \%$ & $2044.30 \%$ & $-27.36 \%$ & $-40.96 \%$ & $0.00 \%$ \\
\hline
\end{tabular}




\section{Table 5: Investment incentives}

This table displays results on the change of the CEO's utility to an increase in the firm's volatility by 0.01 for the different types of contracts, i.e.

$$
\left(E\left[V\left(\phi, n_{S}, n_{O}, \sigma+0.01\right)\right]-E\left[V\left(\phi, n_{S}, n_{O}, \sigma\right)\right]\right) /\left|E\left[V\left(\phi, n_{S}, n_{O}, \sigma\right)\right]\right| .
$$

Panel A shows the mean and the median of this change for four different contracts: the observed contract, the restricted option contract, the unrestricted option contract, and the general nonlinear contract. Panel B contains the proportion of CEOs we classify as risk-neutral under each of the four contracts. We use two different definitions of 'risk-neutral': in the left part of Panel B, we call a CEO 'risk-neutral' if her sensitivity to a 0.01 increase in volatility (as defined above) exceeds -0.01 . In the right part of Panel $A$, we classify a CEO as 'risk-neutral' if the sensitivity exceeds -0.001 . Results are shown for nine different values of the parameter of risk aversion $\gamma$. We only include those $\mathrm{CEO}-\gamma$-combinations, for which we could calculate all three contracts. Results for $\gamma=1$ are not comparable to the results for other values of $\gamma$, because the utility function is not continuous in $\gamma$ at $\gamma=1$.

\section{Panel A: Sensitivity of the CEO's utility to an increase in volatility by 1 percentage point}

\begin{tabular}{|c|c|c|c|c|c|c|c|c|c|}
\hline \multirow{2}{*}{$\begin{array}{c}\text { Risk } \\
\text { aver- } \\
\text { sion }\end{array}$} & \multirow{2}{*}{$\begin{array}{l}\text { No. of } \\
\text { CEOs }\end{array}$} & \multicolumn{2}{|c|}{ Observed contract } & \multicolumn{2}{|c|}{$\begin{array}{c}\text { Restricted option } \\
\text { contract }\end{array}$} & \multicolumn{2}{|c|}{$\begin{array}{c}\text { Unrestricted } \\
\text { option contract }\end{array}$} & \multicolumn{2}{|c|}{$\begin{array}{c}\text { General nonlinear } \\
\text { contract }\end{array}$} \\
\hline & & Mean & Median & Mean & Median & Mean & Median & Mean & Median \\
\hline 0.5 & 594 & $-0.16 \%$ & $-0.13 \%$ & $-0.31 \%$ & $-0.28 \%$ & $-0.49 \%$ & $-0.46 \%$ & $-0.75 \%$ & $-0.72 \%$ \\
\hline 1 & 541 & $-4.42 \%$ & $-0.60 \%$ & $-6.48 \%$ & $-0.99 \%$ & $-8.33 \%$ & $-1.56 \%$ & $-15.61 \%$ & $-2.58 \%$ \\
\hline 2 & 595 & $-1.15 \%$ & $-0.88 \%$ & $-1.46 \%$ & $-1.22 \%$ & $-2.14 \%$ & $-2.00 \%$ & $-5.92 \%$ & $-5.58 \%$ \\
\hline 3 & 596 & $-2.51 \%$ & $-1.90 \%$ & $-3.00 \%$ & $-2.35 \%$ & $-4.42 \%$ & $-3.90 \%$ & $-18.37 \%$ & $-16.15 \%$ \\
\hline 4 & 595 & $-3.81 \%$ & $-2.80 \%$ & $-4.36 \%$ & $-3.39 \%$ & $-6.35 \%$ & $-5.20 \%$ & $-39.67 \%$ & $-32.27 \%$ \\
\hline 5 & 588 & $-4.99 \%$ & $-3.60 \%$ & $-5.55 \%$ & $-4.23 \%$ & $-7.89 \%$ & $-6.03 \%$ & $-77.98 \%$ & $-54.83 \%$ \\
\hline 6 & 578 & $-6.05 \%$ & $-4.28 \%$ & $-6.58 \%$ & $-4.83 \%$ & $-9.04 \%$ & $-6.76 \%$ & $-153.77 \%$ & $-86.16 \%$ \\
\hline 8 & 484 & $-7.73 \%$ & $-5.35 \%$ & $-8.23 \%$ & $-5.92 \%$ & $-10.73 \%$ & $-7.72 \%$ & $-360.41 \%$ & $-208.74 \%$ \\
\hline 10 & 259 & $-8.88 \%$ & $-6.77 \%$ & $-9.43 \%$ & $-7.22 \%$ & $-12.06 \%$ & $-9.06 \%$ & $-1119.35 \%$ & $-530.20 \%$ \\
\hline
\end{tabular}

Panel B: CEO’s attitude towards risk

\begin{tabular}{|c|c|c|c|c|c|c|c|c|}
\hline \multirow{2}{*}{$\begin{array}{c}\text { Risk } \\
\text { aver- } \\
\text { sion }\end{array}$} & \multicolumn{4}{|c|}{ Risk-neutrality defined as sensitivity $>-1 \%$} & \multicolumn{4}{|c|}{ Risk-neutrality defined as sensitivity $>\mathbf{- 0 . 1} \%$} \\
\hline & $\begin{array}{c}\text { Observed } \\
\text { contract }\end{array}$ & $\begin{array}{l}\text { Restricted } \\
\text { option } \\
\text { contract } \\
\end{array}$ & $\begin{array}{c}\text { Unrestricted } \\
\text { option } \\
\text { contract } \\
\end{array}$ & $\begin{array}{c}\text { General } \\
\text { nonlinear } \\
\text { contract }\end{array}$ & $\begin{array}{c}\text { Observed } \\
\text { contract }\end{array}$ & $\begin{array}{c}\text { Restricted } \\
\text { option } \\
\text { contract } \\
\end{array}$ & $\begin{array}{c}\text { Unrestricted } \\
\text { option } \\
\text { contract } \\
\end{array}$ & $\begin{array}{c}\text { General } \\
\text { nonlinear } \\
\text { contract }\end{array}$ \\
\hline 0.5 & $99.66 \%$ & $99.16 \%$ & $97.47 \%$ & $76.09 \%$ & $44.44 \%$ & $15.66 \%$ & $1.85 \%$ & $0.84 \%$ \\
\hline 1 & $65.62 \%$ & $50.28 \%$ & $33.09 \%$ & $19.96 \%$ & $19.78 \%$ & $7.02 \%$ & $1.85 \%$ & $0.92 \%$ \\
\hline 2 & $55.80 \%$ & $40.50 \%$ & $20.17 \%$ & $6.05 \%$ & $9.58 \%$ & $2.69 \%$ & $0.50 \%$ & $0.17 \%$ \\
\hline 3 & $26.34 \%$ & $18.62 \%$ & $8.72 \%$ & $1.34 \%$ & $4.70 \%$ & $0.50 \%$ & $0.00 \%$ & $0.00 \%$ \\
\hline 4 & $17.31 \%$ & $11.43 \%$ & $5.88 \%$ & $0.50 \%$ & $2.69 \%$ & $0.34 \%$ & $0.00 \%$ & $0.00 \%$ \\
\hline 5 & $12.93 \%$ & $8.33 \%$ & $3.40 \%$ & $0.00 \%$ & $2.04 \%$ & $0.17 \%$ & $0.00 \%$ & $0.00 \%$ \\
\hline 6 & $10.21 \%$ & $6.57 \%$ & $2.94 \%$ & $0.00 \%$ & $1.73 \%$ & $0.00 \%$ & $0.00 \%$ & $0.00 \%$ \\
\hline 8 & $6.40 \%$ & $3.51 \%$ & $1.45 \%$ & $0.00 \%$ & $0.62 \%$ & $0.00 \%$ & $0.00 \%$ & $0.00 \%$ \\
\hline 10 & $2.70 \%$ & $1.16 \%$ & $0.77 \%$ & $0.00 \%$ & $0.00 \%$ & $0.00 \%$ & $0.00 \%$ & $0.00 \%$ \\
\hline
\end{tabular}




\section{Table 6: Dismissals and UPPS}

This table shows the change of the CEOs' utility-adjusted pay for performance sensitivity (UPPS) and the change of their expected utility when the threat of being dismissed is taken into account. 'Change in UPPS' is UPPS in the model with threat of dismissal divided by UPPS in the model without threat of dismissal minus one. In order to specify the probability of dismissal, we estimated a logit regression where the dependent variable is equal to one if an executive who is CEO in 1995 leaves the company within the next five years and if ExecuComp records "resigned" as the reason for leaving. The independent variable is the firm's abnormal return over these five years, i.e. the log of the firm's gross return minus the log of the S\&P500 gross return. The parameter estimates (standard errors) are $-2.704(0.136)$ for the intercept and $-0.415(0.077)$ for the slope. The change in expected utility can drop below $-100 \%$, as expected utility is negative for $\gamma>1$. Results for $\gamma=1$ are not comparable to the results for other values of $\gamma$, because the utility function is not continuous in $\gamma$ at $\gamma=1$.

\begin{tabular}{cccccc}
\hline \multirow{2}{*}{$\begin{array}{c}\text { Risk } \\
\text { aversion }\end{array}$} & \multicolumn{2}{c}{ Change in UPPS } & & \multicolumn{2}{c}{ Change in expected utility } \\
\cline { 2 - 3 } \cline { 5 - 6 } & mean & median & & mean & median \\
\hline 0.5 & $-4.17 \%$ & $-4.11 \%$ & & $-2.63 \%$ & $-2.59 \%$ \\
1 & $-2.59 \%$ & $-2.59 \%$ & & $-30.09 \%$ & $-5.67 \%$ \\
2 & $0.96 \%$ & $0.60 \%$ & & $-6.51 \%$ & $-5.95 \%$ \\
3 & $4.85 \%$ & $3.93 \%$ & & $-14.39 \%$ & $-12.62 \%$ \\
4 & $9.06 \%$ & $7.24 \%$ & & $-23.72 \%$ & $-19.87 \%$ \\
5 & $13.62 \%$ & $10.59 \%$ & & $-35.05 \%$ & $-27.64 \%$ \\
6 & $18.64 \%$ & $14.13 \%$ & & $-49.49 \%$ & $-36.22 \%$ \\
8 & $30.51 \%$ & $21.40 \%$ & & $-100.41 \%$ & $-55.17 \%$ \\
10 & $46.18 \%$ & $29.10 \%$ & & $-268.65 \%$ & $-78.44 \%$ \\
\hline
\end{tabular}

\section{Table 7: Optimal contracts with Gamma-distributed stock price}

This table displays the means of six variables that describe the optimal restricted option contract for the alternative model in which the stock price $P_{\mathrm{T}}$ follows a Gamma distribution. The table displays the mean of the three contract parameters: base salary $\phi^{*}$, stock holdings $n_{S}{ }^{*}$ and adjusted option holdings $n_{O}{ }^{*} \exp \{-d T\}$. In addition, it shows the fraction of CEOs with positive option holdings $\left(n_{O^{*}}>0\right)$. Savings are the difference in compensation costs between observed contracts and optimal contracts, $\pi_{0}{ }^{d}-\pi_{0}{ }^{*}$. Savings in percent of total pay are $\left(\pi_{0}{ }^{d}-\pi_{0}{ }^{*}\right) / \pi_{0}{ }^{d}$. Results are shown for nine different values of the parameter of risk aversion $\gamma$. The number of CEOs for whom we could not verify the sufficient condition (17) is shown in the column 'Violations of condit. (17)'.

\begin{tabular}{|c|c|c|c|c|c|c|c|c|}
\hline $\begin{array}{c}\text { Risk } \\
\text { aversion }\end{array}$ & $\begin{array}{l}\text { Number } \\
\text { of CEOs }\end{array}$ & $\begin{array}{c}\text { Violations } \\
\text { of condit. } \\
\text { (17) }\end{array}$ & $\begin{array}{c}\text { Mean base } \\
\text { salary } \\
\left(\$ \text { ' }^{\prime} 000\right) \\
\end{array}$ & $\begin{array}{c}\text { Mean } \\
\text { stock } \\
\text { holdings }\end{array}$ & $\begin{array}{c}\text { Mean } \\
\text { option } \\
\text { holdings }\end{array}$ & $\begin{array}{c}\text { Fraction } \\
\text { with } \\
\text { options }>0\end{array}$ & $\begin{array}{l}\text { Savings } \\
\text { (\$ '000) }\end{array}$ & $\begin{array}{c}\text { Savings in } \\
\text { percent of } \\
\text { total pay }\end{array}$ \\
\hline 0.5 & 584 & 527 & 12,893 & $0.985 \%$ & $2.542 \%$ & $100.00 \%$ & 569 & $0.179 \%$ \\
\hline 1 & 583 & 1 & $-3,610$ & $3.095 \%$ & $0.029 \%$ & $14.75 \%$ & 332 & $0.962 \%$ \\
\hline 2 & 584 & 1 & $-1,845$ & $2.917 \%$ & $0.005 \%$ & $2.23 \%$ & 4,961 & $8.279 \%$ \\
\hline 3 & 584 & 0 & -549 & $2.729 \%$ & $0.001 \%$ & $0.34 \%$ & 11,516 & $16.983 \%$ \\
\hline 4 & 584 & 0 & 292 & $2.592 \%$ & $0.000 \%$ & $0.17 \%$ & 16,577 & $23.535 \%$ \\
\hline 5 & 584 & 0 & 814 & $2.500 \%$ & $0.000 \%$ & $0.17 \%$ & 19,943 & $28.114 \%$ \\
\hline 6 & 584 & 0 & 1,156 & $2.437 \%$ & $0.000 \%$ & $0.17 \%$ & 22,212 & $31.400 \%$ \\
\hline 8 & 584 & 0 & 1,538 & $2.359 \%$ & $0.000 \%$ & $0.17 \%$ & 24,923 & $35.593 \%$ \\
\hline 10 & 584 & 1 & 1,757 & $2.313 \%$ & $0.009 \%$ & $0.34 \%$ & 25,609 & $37.414 \%$ \\
\hline
\end{tabular}




\section{Table 8: Optimal contracts with personal and corporate taxes}

This table displays the means of six variables that describe the optimal restricted option contract for the extended model which takes into account personal and corporate taxes. The table displays the mean of the three contract parameters: base salary $\phi^{*}$, stock holdings $n_{S}{ }^{*}$ and adjusted option holdings $n_{O}{ }^{*} \exp \{-d T\}$. In addition, it shows the fraction of CEOs with positive option holdings $\left(n_{O^{*}}>0\right)$. Savings are the difference in compensation costs between observed contracts and optimal contracts, $\pi_{0}{ }^{d}-\pi_{0}{ }^{*}$. Savings in percent of total pay are $\left(\pi_{0}{ }^{d}-\pi_{0}{ }^{*}\right) / \pi_{0}{ }^{d}$. Results are shown for nine different values of the parameter of risk aversion $\gamma$. The number of CEOs for whom we could not verify the sufficient condition (17) is shown in the column 'Violations of condit. (17)'.

\begin{tabular}{|c|c|c|c|c|c|c|c|c|}
\hline $\begin{array}{c}\text { Risk } \\
\text { aversion }\end{array}$ & $\begin{array}{l}\text { Number } \\
\text { of CEOs }\end{array}$ & $\begin{array}{l}\text { Violations } \\
\text { of condit. } \\
\text { (17) }\end{array}$ & 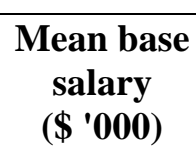 & $\begin{array}{c}\text { Mean } \\
\text { stock } \\
\text { holdings }\end{array}$ & $\begin{array}{c}\text { Mean } \\
\text { option } \\
\text { holdings }\end{array}$ & $\begin{array}{c}\text { Fraction } \\
\text { with } \\
\text { options }>0\end{array}$ & $\begin{array}{l}\text { Savings } \\
(\$ \text { '000) }\end{array}$ & $\begin{array}{l}\text { Savings as } \\
\text { percentage } \\
\text { of total pay }\end{array}$ \\
\hline 0.5 & 593 & 248 & 440 & $2.857 \%$ & $0.494 \%$ & $59.36 \%$ & 301 & $0.943 \%$ \\
\hline 1 & 594 & 146 & -804 & $2.940 \%$ & $0.263 \%$ & $42.93 \%$ & 1,023 & $2.698 \%$ \\
\hline 2 & 597 & 55 & $-1,269$ & $2.870 \%$ & $0.087 \%$ & $19.10 \%$ & 3,655 & $7.990 \%$ \\
\hline 3 & 595 & 26 & -758 & $2.779 \%$ & $0.028 \%$ & $9.58 \%$ & 6,628 & $13.435 \%$ \\
\hline 4 & 595 & 15 & -307 & $2.682 \%$ & $0.036 \%$ & $5.88 \%$ & 8,962 & $17.461 \%$ \\
\hline 5 & 597 & 11 & 169 & $2.600 \%$ & $0.011 \%$ & $4.36 \%$ & 10,981 & $21.176 \%$ \\
\hline 6 & 598 & 7 & 499 & $2.545 \%$ & $0.007 \%$ & $3.18 \%$ & 12,435 & $23.740 \%$ \\
\hline 8 & 598 & 3 & 992 & $2.470 \%$ & $0.003 \%$ & $2.34 \%$ & 14,480 & $27.516 \%$ \\
\hline 10 & 598 & 2 & 1,287 & $2.423 \%$ & $0.002 \%$ & $1.67 \%$ & 15,736 & $29.791 \%$ \\
\hline
\end{tabular}

\section{Table 9: Explaining options by wealth and firm size}

This table displays the results of seven OLS regressions of the proportion of options in risk-neutral pay for performance sensitivity $n_{O}{ }^{d} \cdot \mathrm{N}\left(d_{1}\right) /\left(n_{O}{ }^{d} \cdot \mathrm{N}\left(d_{1}\right)+n_{S}{ }^{d}\right)$ on the log of wealth $W_{0}$, the log of the firm value $P_{0}$, the firm's stock volatility, and the CEO's age and job tenure. All regressions include an intercept (results not shown). The table displays the slope estimates and their standard errors in parentheses. $*$ indicates significance at the $5 \%$ level. $* *$ indicates significance at the $1 \%$ level.

\begin{tabular}{|c|c|c|c|c|c|c|c|}
\hline $\begin{array}{c}\text { Independent } \\
\text { Variable }\end{array}$ & (1) & (2) & (3) & (4) & (5) & (6) & (7) \\
\hline $\log (\mathrm{W} 0)$ & $\begin{array}{c}-0.0510^{* *} \\
(0.0084)\end{array}$ & & & $\begin{array}{c}-0.0855^{* *} \\
(0.0092)\end{array}$ & & & $\begin{array}{c}-0.0924 * * \\
(0.0136)\end{array}$ \\
\hline $\log (\mathbf{P 0})$ & & $\begin{array}{c}0.0215^{* *} \\
(0.0069)\end{array}$ & & $\begin{array}{c}0.0608 * * \\
(0.0078)\end{array}$ & & & $\begin{array}{c}0.0634^{* *} \\
(0.0114)\end{array}$ \\
\hline Volatility & & & $\begin{array}{c}0.0314 \\
(0.0617)\end{array}$ & $\begin{array}{c}0.2206^{* *} \\
(0.0617)\end{array}$ & & & $\begin{array}{l}0.2759^{*} \\
(0.1310)\end{array}$ \\
\hline Age & & & & & $\begin{array}{c}-0.0071^{* *} \\
(0.0017)\end{array}$ & & $\begin{array}{c}0.0018 \\
(0.0026)\end{array}$ \\
\hline Tenure & & & & & & $\begin{array}{c}-0.0070^{* *} \\
(0.0015)\end{array}$ & $\begin{array}{c}-0.0057^{* *} \\
(0.0017)\end{array}$ \\
\hline Adjusted R2 & 0.0568 & 0.0143 & -0.0012 & 0.1417 & 0.0275 & 0.0697 & 0.2102 \\
\hline Observations & 598 & 598 & 598 & 598 & 560 & 289 & 268 \\
\hline
\end{tabular}

